\title{
Transient response of near-wellbore supercharging during filter cake growth
}

\author{
Tianshou $\mathrm{Ma}^{1,2}$, Nian Peng ${ }^{1, *}$, Ping Chen ${ }^{1,{ }^{*}}$, and Yang $\mathrm{Liu}^{3}$ \\ ${ }^{1}$ State Key Laboratory of Oil and Gas Reservoir Geology and Exploitation, Southwest Petroleum University, Chengdu, 610500 \\ Sichuan, PR China \\ ${ }^{2}$ State Key Laboratory of Geomechanics and Geotechnical Engineering, Institute of Rock and Soil Mechanics, \\ Chinese Academy of Sciences, Wuhan, 430071 Hubei, PR China \\ ${ }^{3}$ School of Mechatronic Engineering, Southwest Petroleum University, Chengdu, 610500 Sichuan, PR China
}

Received: 30 October 2020 / Accepted: 6 May 2021

\begin{abstract}
Supercharging in the vicinity of a borehole is an important factor that affects formation damage and drilling safety, and the filter cake growth process has a significant impact on supercharging in the vicinity of the borehole. However, existing models that predict pore pressure distribution overlook dynamic filter cake growth. Thus, an analytical supercharging model was developed that considers time-dependent filter cake effects, and this model was verified using a two-dimensional numerical model. The influences of filter cake, formation, and filtrate properties on supercharging were investigated systematically. The results indicate that time-dependent filter cake effects have significant influence on supercharging. Supercharging increases in the early stage but decreases over time because of the dynamic growth of filter cake, and the supercharging magnitude decreases along the radial direction. Because of filter cake growth, the magnitude of supercharging falls quickly across the filter cake, and the decreased magnitude of pore pressure caused by the filter cake increases. Supercharging in low-permeability formations is more obvious and the faster rate of filter cake growth, a lower filtrate viscosity and faster reduction rate of filter cake permeability can help to weaken supercharging. The order of importance of influencing factors on supercharging is overbalance pressure $>$ formation permeability $>$ formation porosity $\approx$ filtrate viscosity $>$ filter cake permeability attenuation coefficient $>$ initial filter cake permeability control ratio $>$ filter cake growth coefficient $>$ filter cake porosity. To alleviate supercharging in the vicinity of the borehole, adopting drilling fluids that allow a filter cake to form quickly, optimizing drilling fluid with a lower filtrate viscosity, keeping a smaller overbalance pressure, and precise operation at the rig site are suggested for low-permeability formations during drilling.
\end{abstract}

\section{Introduction}

Pore pressure, also known as formation pressure, is the pressure of the fluid in the pore spaces of porous formations (Ma et al., 2015). As a key parameter in geology-related fields, accurate pore pressure prediction is vital for geological scientists and engineers. It is well known that many activities, such as drilling, tunnel excavation, seismicity, geological energy exploitation and storage, and geological disposal of nuclear waste, can cause pore pressure to change, which may further change the structure and stress state of porous materials and may lead to shear failure or fracturing (Bruno and Nakagawa, 1991; Guayacán-Carrillo et al., 2017; Liu et al., 2013, 2020; Mohajerani et al., 2012; Rice, 2006; Shi et al., 2021). In drilling engineering, there are many factors that can result in pore pressure variation near the wellbore, and these factors can be classified into physical (e.g., fluid flow into or out of the formation, time-dependent filter cake growth, capillary action, and hydrodynamic expansion), mechanical (e.g., drilling unloading, temperature change-induced thermal stress, and in-situ stressinduced stress concentration near the wellbore), chemical (e.g., interaction between the rock and drilling fluid), and engineering effects (e.g., surge/swab pressure during tripping operations, drill-string rotation or vibration, and the drill string colliding with the wellbore wall) (Jia et al., 2019; Khaled and Shokir, 2017; Ma et al., 2016; Meng et al., 2019; Roshan and Rahman, 2010).

One of the main reasons for pore pressure variations in the vicinity of the borehole is that drilling fluid filtrate invasion occurs as the mud hydrostatic pressure is set higher than the original formation pressure to ensure drilling safety

\footnotetext{
* Corresponding authors: peng_nian@126.com; chenping@swpu.edu.cn
} 
(Banerjee et al., 2006; Ceyhan et al., 2016; Di et al., 2014). This in turn leads to higher pore pressure near the wellbore than the original formation pressure, especially in lowpermeability formations, which is also called supercharging. The supercharging phenomenon in the vicinity of the borehole is significant because it is a prerequisite for analyzing wellbore stability, reservoir damage, and formation testing while drilling; thus, numerous works have been conducted on this topic. It should be noted during drilling that the pressure differential between the wellbore and the formation causes the mud filtrate to invade the formation while depositing solid particles at the wellbore wall to form a filter cake (Banerjee et al., 2006; Ma et al., 2020); a schematic description of the pressure profile with supercharging in the vicinity of the borehole is provided in Figure 1, which shows that the pressure in the wellbore is at hydrostatic pressure $\left(p_{w}\right)$ but falls quickly across the filter cake $\left(p_{a}\right)$ and then slowly decreases in the formation to the original formation pressure $\left(p_{i}\right)$ some distance away from the wellbore (Banerjee et al., 2006; Hadibeik et al., 2012).

During the process of filter cake growth, the cake thickness increases and permeability decreases over time until they stabilize to a maximum thickness and a minimum permeability. It is necessary to consider time-dependent filter cake effects (including filter cake thickness and permeability) on the supercharging phenomenon in the vicinity of the borehole because filter cake properties have a direct influence on hydraulic and mechanical effects near the wellbore (Di et al., 2014; Feng et al., 2018b; Liu and Abousleiman, 2018; Tran et al., 2011). However, only a few works have considered the influence of time-dependent filter cake effects on supercharging analyses. Traditional models for wellbore stability research have considered either a wellbore with an impermeable filter cake or one with no filter cake at all (Halafawi and Avram, 2019; Meng et al., 2019; Roshan and Rahman, 2010, 2011; Ubedullah et al., 2019). In reservoir damage analysis of over-balanced drilling, the main damage types include water locking damage, sensitivity damage, and solid phase invasion damage, and those damages are influenced directly by the drilling fluid invasion process (Dabiri et al., 2013; Li et al., 2017; Zheng et al., 2019), which means that the formation damage is closely related to filter cake time-dependent properties. In addition, the invasion radius is an important parameter to describe the degree of formation damage (Civan, 2016; Ling et al., 2015; Parn-anurak and Engler, 2005 ), and this radius can be visualized more intuitively according to the supercharging distribution near the wellbore. However, such analytical models are scarce, and supercharging in the vicinity of the borehole has not aroused much attention. Furthermore, in formation testing while drilling, which is commonly used in offshore drilling to improve drilling safety and reduce the drilling time and cost (Di et al., 2014), although some models have considered filter cake properties, filter cake thickness and permeability were not involved simultaneously or were not considered as time-dependent properties (Banerjee et al., 2006; Hammond and Pop, 2005). There are also other numerical models in which the time-dependent filter cake properties were both considered (Feng et al., 2018a; Chang et al., 2008;

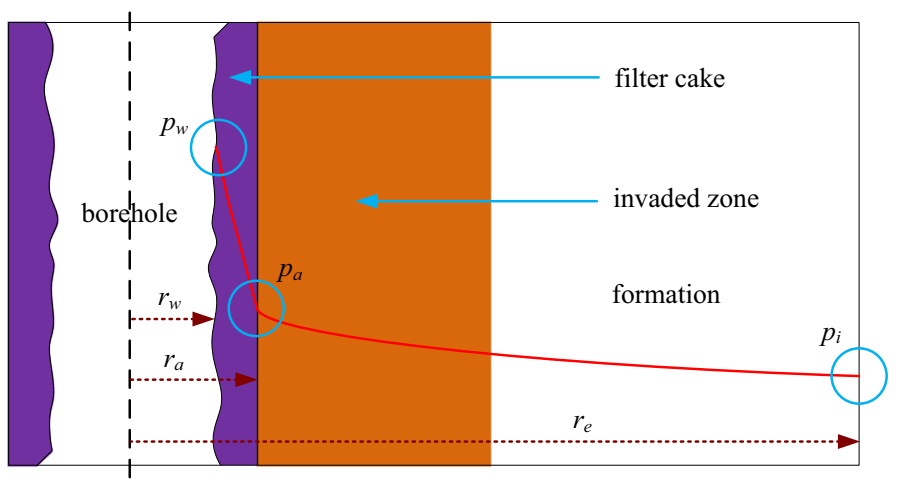

Fig. 1. Pressure with the supercharging effect in the vicinity of the borehole (modified from Ma et al., 2015).

Zaher and Sirju, 2014), but such models would need a complex initialization process and would spend a considerable amount of time on calculation.

With the development of unconventional resources exploitation, the numbers of deep wells, ultra-deep wells, and extended reach wells continue to increase, leading to increased costs and risks of drilling. The effects of filter cake buildup and/or filter cake property variation over time on supercharging-related wellbore stability, reservoir damage, and formation testing while drilling have been plaguing the industry, and analytical solutions for supercharging in the vicinity of the borehole involving time-dependent filter cake effects are very limited. To fill this gap, an analytical model of transient response of near-wellbore supercharging during filter cake growth is proposed in this paper, and the influencing factors of supercharging have been systematically investigated. The results of this paper can help us to understand the variation rules of supercharging, and to guide the analysis of wellbore stability, reservoir damage, and formation testing during drilling.

The paper is organized as follows. In Section 2, a new model is first proposed that considers time-dependent filter cake thickness and permeability. The model is then verified by comparing the analytical results with the simulation results calculated by COMSOL Multiphysics. In Section 3, the influences of filter cake parameters, formation properties, and filtrate viscosity on supercharging in the vicinity of the borehole are investigated systematically. In Section 4, the supercharging variation rules of four special cases, the influencing degrees of different factors on supercharging, and strategies to weaken supercharging are discussed, and the limitations of the model are also described.

\section{Modeling}

\subsection{Problem description and assumptions}

In drilling process, at the moment when the drill bit crushing the rock at the bottom hole, the drilling fluids permeate into the formation immediately due to the overbalanced pressure between wellbore and formation, and the filter 


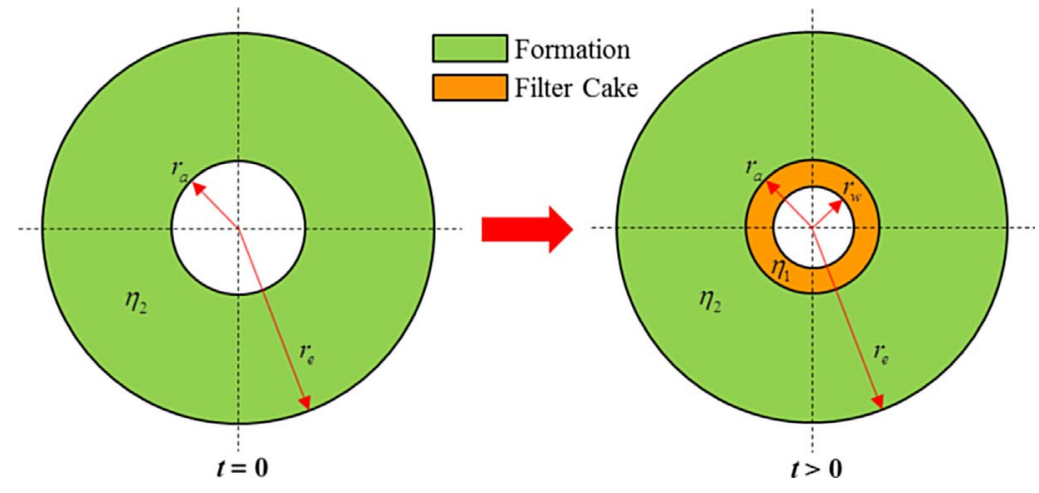

Fig. 2. Diagram of filter cake and formation.

cake has not formed yet at this moment. With increasing time, the drilling fluids continue to filter into the formation, and because of irregular protrusion on the inner wall of the wellbore, some solid particles in the drilling fluids will gradually adhere to the borehole wall and form the filter cake (Fisher et al., 2000; Ma et al., 2020). During those time, the invaded small sized particle will block the pore throat, which will result in a smaller permeability of filter cake as time increasing. Because of the thicker thickness and smaller permeability of the filter cake, the filtration rate and the cake growth rate gradually decrease, and then reach a dynamic equilibrium state after a period of time (Jaffal et al., 2017; Liu and Santamarina, 2018). A diagram of the filter cake and formation is shown in Figure 2. Because the filter cake has a direct influence on hydraulic and mechanical effects near the wellbore, supercharging in the vicinity of the borehole during drilling is also timedependent based on filter cake thickness and permeability. To simplify the modeling process of supercharging, the following assumptions are made:

1. The formation is continuous, homogeneous, and isotropic, and its porosity and permeability are constant.

2. The fluid flow process satisfies single-phase incompressible Darcy flow.

3. The porosity of the filter cake is constant during the cake growth process.

4. The overbalance pressure between the wellbore and formation is also constant.

5. Thermal and chemical effects on supercharging near the wellbore can be ignored.

\subsection{Equivalent filter cake permeability}

Filter cake thickness increases with time during drilling, which means that the inner boundary conditions, such as the radius of the inner boundary $\left(r_{w}\right)$ shown in Figure 2, change with time. It is challenging to build an analytical model of this system when moving boundary conditions are considered. Therefore, we have adopted a single material parameter, named "equivalent filter cake permeability" by Feng et al. (2018a), to capture the effects of both time-dependent filter cake thickness and permeability on supercharging. The equivalent filter cake permeability can be determined by forcing the same fluid flow rate under the same differential pressure across the filter cake in equivalent conditions with a constant filter cake thickness $w_{o}$ and the real case with time-dependent filter cake thickness $w_{1}(t)$ and permeability $k_{1}(t)$. Thus, the following equation can be obtained (Feng et al., 2018a):

$$
\frac{2 \pi k_{e}(t)}{\mu \ln \frac{r_{w}+w_{0}}{r_{w}}} \Delta p=\frac{2 \pi k_{1}(t)}{\mu \ln \frac{r_{w}+w_{1}(t)}{r_{w}}} \Delta p .
$$

The left side of this equation represents the flow rate in the equivalent conditions with a constant filter cake thickness $w_{o}$ and time-dependent equivalent filter cake permeability $k_{e}(t)$, and the right side represents the flow rate for the real situation with time-dependent filter cake thickness $w_{1}(t)$ and permeability $k_{1}(t)$. Thus, according to equation (1), the equivalent filter cake permeability $k_{e}(t)$ can be written as:

$$
k_{e}(t)=k_{1}(t) \frac{\ln \left(1+\frac{w_{o}}{r_{w}}\right)}{\ln \left(1+\frac{w_{1}(t)}{r_{w}}\right)},
$$

where $k_{e}(t)$ is the equivalent filter cake permeability, $\mathrm{mD}$; $k_{1}$ is the real situation with time-dependent filter cake permeability, $\mathrm{mD} ; w_{o}$ is the constant filter cake thickness, m; $w(t)$ is the real situation with time-dependent filter cake thickness, $\mathrm{m}$; and $r_{w}$ is the filter cake inner radius, $\mathrm{m}$.

During drilling, many factors such as drill-string rotational speed, annulus velocity, drilling fluid type, solid particle size, formation temperature, formation pressure, and formation permeability, can influence the time-dependent properties of the filter cake (Jaffal et al., 2018; Ma et al., 2020; Ribeiro et al., 2017; Veisi et al., 2020; Yao et al., 2014). Some experimental and mathematical models have been conducted to study the filter cake growth process (Fisher et al., 2000; Hashemzadeh and Hajidavalloo, 2016; Jaffal et al., 2017; Ma et al., 2020; Rabbani and Salehi, 2017), and their results showed that both the thickness and permeability of filter cake obey the exponential changing 
modes. Some previous researchers have utilized the empirical equations with the exponential changing modes to investigate the time-dependent filter cake effects on wellbore stresses (Feng et al., 2018a; Tran et al., 2011), but the coefficients of their empirical equations are constant, which can only be used in some special cases. In order to enlarge the application scope of those equations, the following general empirical equations were adopted to describe the time-dependent filter cake permeability and thickness. It should be noted that the coefficients of both two equations can be obtained from the curve fitting with the indoor experimental data or simulated result of their own interest:

$$
\begin{gathered}
k_{1}(t)=a \cdot\left(1+b \cdot e^{-c t}\right), \\
w_{1}(t)=d \cdot\left(1-e^{-m t}\right),
\end{gathered}
$$

where $a$ is the final filter cake permeability, $\mathrm{mD} ; b$ is the initial filter cake permeability control ratio, dimensionless; $c$ is the permeability attenuation coefficient of the filter cake, dimensionless; $d$ is the final filter cake thickness, $\mathrm{m}$; and $m$ is the filter cake growth coefficient, dimensionless.

\subsection{Mathematical model of supercharging}

Because the research object is a combined filter cake formation system, according to the assumptions in Section 2.1, the governing equations of the filter cake and formation in a radial cylindrical system can be written as:

$$
\left\{\begin{array}{l}
\frac{\partial^{2} p_{1}}{\partial r^{2}}+\frac{1}{r} \frac{\partial p_{1}}{\partial r}=\frac{\phi_{1} \mu_{1} c_{t 1}}{k_{e}} \frac{\partial p_{1}}{\partial t}=\frac{1}{\eta_{1}} \frac{\partial p_{1}}{\partial t} \quad\left(r_{w} \leq r \leq r_{a}\right) \\
\frac{\partial^{2} p_{2}}{\partial r^{2}}+\frac{1}{r} \frac{\partial p_{2}}{\partial r}=\frac{\phi_{2} \mu_{2} c_{t 2}}{k_{2}} \frac{\partial p_{2}}{\partial t}=\frac{1}{\eta_{2}} \frac{\partial p_{2}}{\partial t} \quad\left(r_{a} \leq r \leq r_{e}\right),
\end{array}\right.
$$

where $r$ is the radius, $\mathrm{m} ; t$ is time, $\mathrm{s} ; p_{1}$ is the pore pressure in the filter cake, $\mathrm{Pa} ; \phi_{1}$ is the filter cake porosity, dimensionless; $\mu_{1}$ is the filtrate viscosity in the filter cake, Pa.s; $c_{t 1}$ is the filter cake compressibility, $1 / \mathrm{Pa} ; \eta_{1}$ is the hydraulic diffusivity of the filter cake, $\mathrm{m}^{2} / \mathrm{s} ; p_{2}$ is the pore pressure in the formation, $\mathrm{Pa} ; \phi_{2}$ is the formation porosity, dimensionless; $\mu_{2}$ is the filtrate viscosity in the formation, Pa.s; $c_{t 2}$ is the formation compressibility, $1 / \mathrm{Pa} ; k_{2}$ is the formation permeability, $\mathrm{mD} ; \eta_{2}$ is the formation hydraulic diffusivity, $\mathrm{m}^{2} / \mathrm{s} ; r_{a}$ is the formation inner radius, $\mathrm{m}$; and $r_{e}$ is the formation outer radius, $\mathrm{m}$.

The initial condition is:

$$
p(r, 0)=p_{i},
$$

where, $P_{i}$ is the original formation pressure, $\mathrm{Pa}$.

The boundary conditions are:

$$
\begin{cases}p(r, t)=p_{i}+\Delta p & \left(r=r_{\mathrm{w}}\right) \\ p(r, t)=p_{i} & \left(r=r_{e}\right),\end{cases}
$$

where $\Delta P$ is the overbalance pressure between the wellbore and formation, $\mathrm{Pa}$.

In addition, the continuity conditions are as follows:

$$
\begin{cases}p_{1}(r, t)=p_{2}(r, t) & \left(r=r_{a}\right) \\ \frac{k_{e}}{\mu_{1}} \frac{\partial p_{1}}{\partial r}=\frac{k_{2}}{\mu_{2}} \frac{\partial p_{2}}{\partial r} \quad\left(r=r_{a}\right) .\end{cases}
$$

To simplify the calculation, the following dimensionless variables (including dimensionless time $t_{D}$, dimensionless pressure $p_{D}$, and the dimensionless radius $r_{D}$ ) are introduced:

$$
\begin{gathered}
t_{D}=\frac{\eta_{2} \cdot t}{\left(r_{a}-w_{0}\right)^{2}}, \\
p_{D}=\frac{p-p_{i}}{\Delta p}, \\
r_{D}=\frac{r}{r_{a}-w_{0}} .
\end{gathered}
$$

Therefore, equation (5) becomes:

$$
\left\{\begin{array}{cl}
\frac{\partial^{2} p_{D 1}}{\partial r_{D}^{2}}+\frac{1}{r_{D}} \frac{\partial p_{D 1}}{\partial r_{D}}=\delta \frac{\partial p_{D 1}}{\partial t_{D}} & \left(\frac{r_{w}}{\left(r_{a}-w_{0}\right)} \leq r_{D} \leq \frac{r_{a}}{\left(r_{a}-w_{0}\right)}\right) \\
\frac{\partial^{2} p_{D 2}}{\partial r_{D}{ }^{2}}+\frac{1}{r_{D}} \frac{\partial p_{D 2}}{\partial r_{D}}=\frac{\partial p_{D 2}}{\partial t_{D}} \quad\left(\frac{r_{a}}{\left(r_{a}-w_{0}\right)} \leq r_{D} \leq \frac{r_{e}}{\left(r_{a}-w_{0}\right)}\right) .
\end{array}\right.
$$

In which,

$$
\delta=\frac{\eta_{2}}{\eta_{1}}
$$

Equations (6)-(8) then respectively become:

$$
\begin{gathered}
p_{D}\left(r_{D}, 0\right)=0, \\
\left\{\begin{array}{l}
p_{D 1}\left(\frac{r_{w}}{\left(r_{a}-w_{0}\right)}, t\right)=1 \\
p_{D 1}\left(\frac{r_{e}}{\left(r_{a}-w_{0}\right)}, t\right)=0,
\end{array}\right. \\
\left\{\begin{array}{l}
p_{D 1}=p_{D 2}\left(\frac{r_{a}}{\left(r_{a}-w_{0}\right)}, t_{D}\right) \\
\frac{\partial p_{D 1}}{\partial r_{D}}=M \frac{\partial p_{D 2}}{\partial r_{D}}\left(\frac{r_{a}}{\left(r_{a}-w_{0}\right)}, t_{D}\right) .
\end{array}\right.
\end{gathered}
$$

In equation (16), $M$ is:

$$
M=\frac{k_{2} \mu_{1}}{k_{e} \mu_{2}} .
$$

Applying Laplace transformation to equation (12) and (14)-(16) yields: 


$$
\left[\begin{array}{cccc}
I_{0}(\sqrt{\delta s}) & K_{0}(\sqrt{\delta s}) & 0 & 0 \\
0 & 0 & I_{0}\left(\frac{r_{e} \sqrt{s}}{r_{a}-w_{0}}\right) & K_{0}\left(\frac{r_{e} \sqrt{s}}{r_{a}-w_{0}}\right) \\
I_{0}\left(\frac{r_{a} \sqrt{\delta s}}{r_{\mathrm{a}}-w_{0}}\right) & K_{0}\left(\frac{r_{a} \sqrt{\delta s}}{r_{a}-w_{0}}\right) & -I_{0}\left(\frac{r_{a} \sqrt{s}}{r_{a}-w_{0}}\right) & -K_{0}\left(\frac{r_{a} \sqrt{s}}{r_{a}-w_{0}}\right) \\
\sqrt{\delta s} I_{1}\left(\frac{r_{a} \sqrt{\delta s}}{r_{a}-w_{0}}\right) & -\sqrt{\delta s} K_{1}\left(\frac{r_{a} \sqrt{\delta s}}{r_{a}-w_{0}}\right) & -M \sqrt{s} I_{1}\left(\frac{r_{a} \sqrt{s}}{r_{a}-w_{0}}\right) & M \sqrt{s} K_{1}\left(\frac{r_{a} \sqrt{s}}{r_{a}-w_{0}}\right)
\end{array}\right] \times\left[\begin{array}{c}
A \\
B \\
C \\
D
\end{array}\right]=\left[\begin{array}{c}
1 / s \\
0 \\
0 \\
0
\end{array}\right] .
$$

$$
\left\{\begin{array}{c}
\frac{\mathrm{d}^{2} \bar{p}_{D 1}}{\mathrm{~d}\left(r_{D} \sqrt{\delta s}\right)^{2}}+\frac{1}{r_{D} \sqrt{\delta s}} \frac{\mathrm{d} \bar{p}_{D 1}}{\mathrm{~d}\left(r_{D} \sqrt{\delta s}\right)}-\bar{p}_{D 1}=0 \\
\left(\frac{r_{w}}{\left(r_{a}-w_{0}\right)} \leq r_{D} \leq \frac{r_{a}}{\left(r_{a}-w_{0}\right)}\right) \\
\frac{\mathrm{d}^{2} \bar{p}_{D 2}}{\mathrm{~d}\left(r_{D} \sqrt{s}\right)^{2}}+\frac{1}{r_{D} \sqrt{s}} \frac{\mathrm{d} \bar{p}_{D 2}}{\mathrm{~d}\left(r_{D} \sqrt{s}\right)}-\bar{p}_{D 2}=0 \\
\left(\frac{r_{a}}{\left(r_{a}-w_{0}\right)} \leq r_{D} \leq \frac{r_{e}}{\left(r_{a}-w_{0}\right)}\right)
\end{array}\right.
$$

where $s$ is the complex variable in a Laplace transform:

$$
\begin{gathered}
\bar{p}_{D}\left(r_{D}, s\right)=0, \\
\left\{\begin{array}{l}
\bar{p}_{D 1}\left(r_{w} /\left(r_{a}-w_{0}\right), s\right)=\frac{1}{s} \\
\bar{p}_{D 2}\left(r_{e} /\left(r_{a}-w_{0}\right), s\right)=0,
\end{array}\right. \\
\left\{\begin{array}{l}
\bar{p}_{D 1}=\bar{p}_{D 2} \quad\left(r_{a} /\left(r_{a}-w_{0}\right), s\right) \\
\frac{\mathrm{d} \bar{p}_{D 1}}{\mathrm{~d} r_{D}}=M \frac{\mathrm{d} \bar{p}_{D 2}}{\mathrm{~d} r_{D}} \quad\left(r_{a} /\left(r_{a}-w_{0}\right), s\right) .
\end{array}\right.
\end{gathered}
$$

Equation (18) comprises modified Bessel equations, the solutions of which in the Laplace domain are:

$$
\left\{\begin{array}{c}
\bar{p}_{D 1}=A I_{0}\left(r_{D} \sqrt{\delta s}\right)+B K_{0}\left(r_{D} \sqrt{\delta s}\right) \\
\left(\frac{r_{w}}{\left(r_{a}-w_{0}\right)} \leq r_{D} \leq \frac{r_{a}}{\left(r_{a}-w_{0}\right)}\right) \\
\bar{p}_{D 2}=C I_{0}\left(r_{D} \sqrt{s}\right)+D K_{0}\left(r_{D} \sqrt{s}\right) \\
\left(\frac{r_{a}}{\left(r_{a}-w_{0}\right)} \leq r_{D} \leq \frac{r_{e}}{\left(r_{a}-w_{0}\right)}\right)
\end{array}\right.
$$

where $I_{0}()$ and $K_{0}()$ are the first and second kind zeroorder modified Bessel functions, respectively, and $A, B$, $C$, and $D$ are undetermined coefficients.

Taking the derivative of equation (22) yields:

$$
\left\{\begin{array}{c}
\frac{\mathrm{d} \bar{p}_{D 1}}{\mathrm{~d} r_{D}}=A \sqrt{\delta s} I_{1}\left(r_{D} \sqrt{\delta s}\right)-B \sqrt{\delta s} K_{1}\left(r_{D} \sqrt{\delta s}\right) \\
\left(\frac{r_{w}}{\left(r_{a}-w_{0}\right)} \leq r_{D} \leq \frac{r_{a}}{\left(r_{a}-w_{0}\right)}\right) \\
\frac{\mathrm{d} \bar{p}_{D 2}}{\mathrm{~d} r_{D}}=C \sqrt{s} I_{1}\left(r_{D} \sqrt{s}\right)-D \sqrt{s} K_{1}\left(r_{D} \sqrt{s}\right) \\
\left(\frac{r_{a}}{\left(r_{a}-w_{0}\right)} \leq r_{D} \leq \frac{r_{e}}{\left(r_{a}-w_{0}\right)}\right),
\end{array}\right.
$$

where $I_{1}()$ and $K_{1}()$ are the first and second kind firstorder modified Bessel functions, respectively.

Now, we can unite equations (20)-(23), and after some derivations, the following matrix can be obtained:

\section{see equation (24) top of the page}

The solutions of equation (24) can be easily obtained using a linear algebra method, such as the Gaussian main elimination method. After $A, B, C$, and $D$ are obtained, submitting these parameters into equation (22), we can determine the pore pressure near the wellbore in Laplace space.

Because of the difficulty of inverse Laplace transformation, the Stehfest inversion method is used to obtain the supercharging pressure in real space:

$$
p_{D}\left(r_{D}, t_{D}, \delta\right)=\frac{\ln 2}{t_{D}} \sum_{i=1}^{N} v_{\mathrm{i}} \cdot \bar{p}_{D}\left(r_{D}, \frac{\ln 2}{t_{D}} i, \delta\right),
$$

where $N$ is an even number $(N=8)$, and $s$ in equation (22) is represented by $\frac{\ln 2}{t_{D}} i$.

It should be noted that the supercharging pressure calculated by equation (25) is the one at a certain moment. Hydraulic conditions vary with time, which frustrates any simple calculation of supercharging, but it is possible to make an approximate estimate based on the assumption that the filter cake has taken its present value at all times since the start of drilling when calculating supercharging pressure in the vicinity of the borehole at a certain moment.

A special case of the current model is that when $\delta=1$, the combined filter cake-formation system can degenerate into a system without filter cake; thus, the model can also be used to study the supercharging phenomenon under that condition.

\subsection{Model validation and comparison}

To validate the supercharging model proposed in this paper, a 2D combined filter cake-formation numerical model was created using commercial finite-element software (COMSOL Multiphysics). Because of symmetry, only one quarter of the wellbore was modeled, as shown in Figure 3. The length and width of the whole model were 20 times the filter cake inner radius, and the mesh in the wellbore vicinity was refined to better capture the pore pressure variations in this region. The basic parameters used in both the numerical and analytical models are list in Table 1. For simulating the supercharging phenomenon under the 

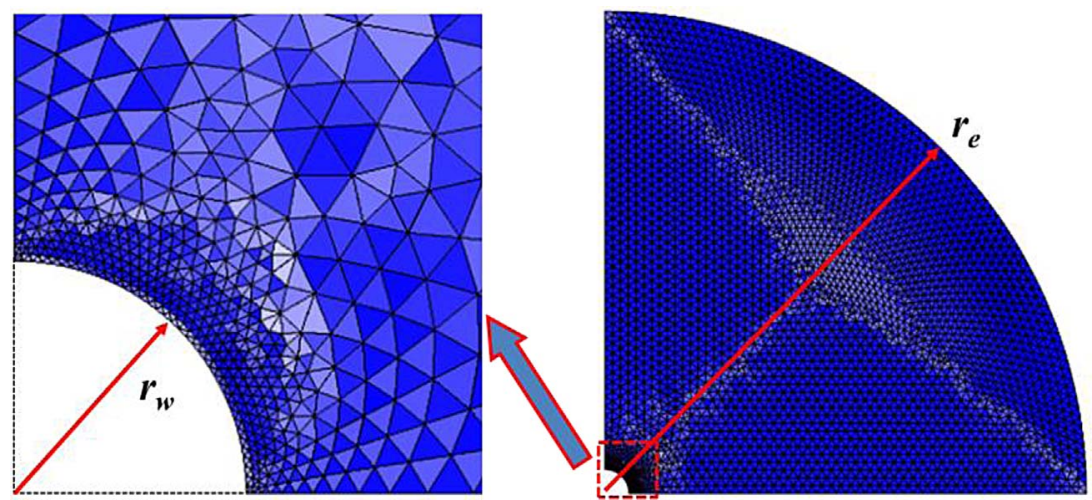

Fig. 3. Geometry and mesh of the numerical model.

Table 1. Basic parameters.

\begin{tabular}{lccc}
\hline No. & Parameters & Value & Unit \\
\hline 1 & Filter cake inner radius, $r_{w}$ & 0.1 & $\mathrm{~m}$ \\
2 & Formation inner radius, $r_{a}$ & 0.103 & $\mathrm{~m}$ \\
3 & Formation outer radius, $r_{e}$ & 2 & $\mathrm{~m}$ \\
4 & Constant mudcake thickness, $w_{o}$ & 0.003 & $\mathrm{~m}$ \\
5 & Original formation pressure, $P_{i}$ & $10^{7}$ & $\mathrm{~Pa}$ \\
6 & Overbalance pressure, $\Delta P$ & $3 \times 10^{6}$ & $\mathrm{~Pa}$ \\
7 & Filter cake porosity, $\phi_{1}$ & 0.08 & - \\
8 & Filter cake compressibility, $c_{t 1}$ & $4 \times 10^{-10}$ & $1 / \mathrm{Pa}$ \\
9 & Filtrate viscosity in filter cake, $\mu_{1}$ & 0.001 & $\mathrm{~Pa} \cdot \mathrm{s}$ \\
10 & Filter cake thickness, $w_{1}$ & $w_{o}\left(1-\mathrm{e}^{-0.002 t}\right)$ & $\mathrm{m}$ \\
11 & Filter cake permeability, $k_{1}$ & $0.0005\left(1+3 \mathrm{e}^{-0.0005 t}\right)$ & $\mathrm{mD}$ \\
12 & Formation porosity, $\phi_{2}$ & 0.1 & - \\
13 & Formation compressibility, $c_{t 2}$ & $1 \times 10^{-10}$ & $1 / \mathrm{Pa}$ \\
14 & Filtrate viscosity in formation, $\mu_{2}$ & 0.001 & $\mathrm{~Pa} \cdot \mathrm{s}$ \\
15 & Formation permeability, $k_{2}$ & 0.1 & $\mathrm{mD}$ \\
\hline
\end{tabular}

condition that no filter cake exists on the borehole wall, the filter properties were replaced by the formation properties. The numerical and analytical results of supercharging in the vicinity of the borehole within/without filter cake effects are depicted in Figures 4a and 4b respectively. A close agreement of the results of the two models can be observed, which confirms that the analytical model and solution process proposed in this paper are exact enough. From Figure 4, it is easily observed that the supercharging in the vicinity of the borehole was very different when the time-dependent filter cake properties were considered compared with the condition of no filter cake. When the filter cake was involved, the supercharging near the wellbore decreased with time as the filter cake grew during drilling. However, the supercharging increased with increasing time when the filter cake was not considered. Therefore, it is necessary to consider time-dependent filter cake effects on supercharging in the vicinity of the borehole to study wellbore stability, reservoir damage, or formation testing while drilling.

\section{Evolution of supercharging with different factors}

The supercharging phenomenon near the wellbore is closely related to filter cake, formation, and filtrate properties. To reveal the supercharging variation rules with different influencing factors when time-dependent filter cake effects are considered, according to the basic data in Table 1 , the supercharging near the wellbore under different filter cake properties (including the permeability attenuation coefficient, initial permeability control ratio, and growth coefficient), formation properties (including permeability and porosity), and filtrate viscosity were systematically investigated.

\subsection{Filter cake permeability attenuation coefficient}

The filter cake permeability attenuation coefficient controls the permeability reduction rate of the filter cake, and the permeability reduction rate directly influences the hydraulic 

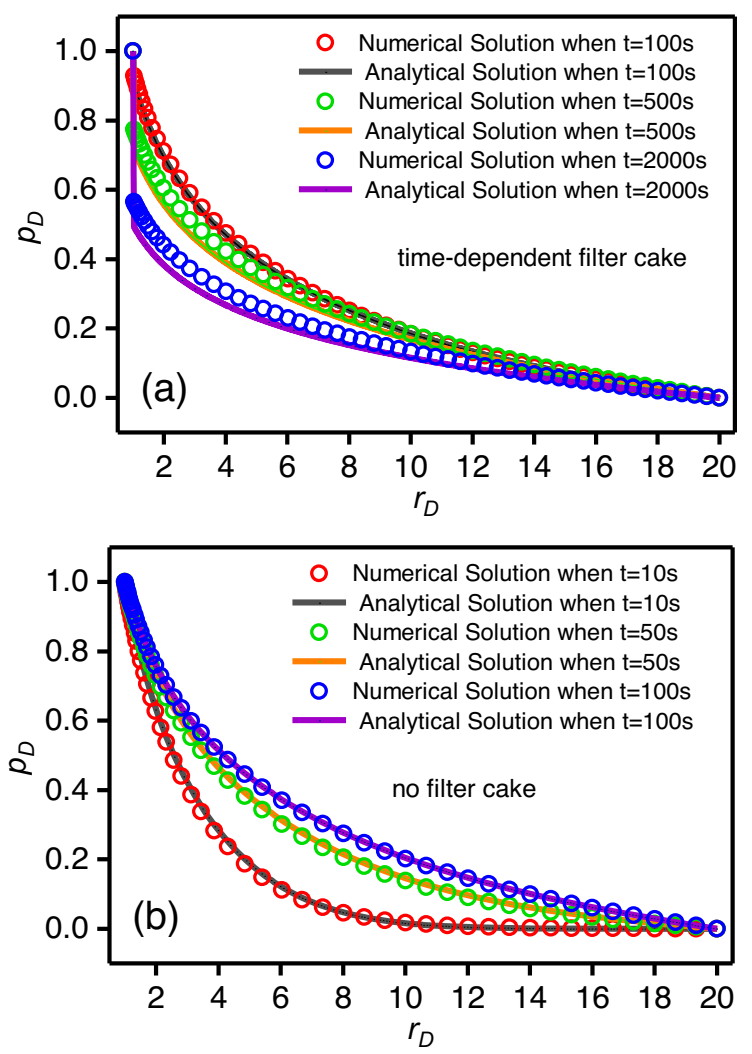

Fig. 4. Analytical and numerical results comparison. (a) Timedependent filter cake; (b) no filter cake.

diffusion efficiency between the wellbore and formation. To study the effect of the filter cake permeability attenuation coefficient on supercharging near the wellbore, the pore pressure variations were analyzed for different filter cake permeability attenuation coefficients of $0.0004,0.0006$, 0.0008, and 0.0010. Supercharging with different times and positions near the wellbore are depicted in Figures 5 and 6 , respectively.

Figure 5 shows that the supercharging pressure decreased gradually along the radial direction and fell quickly across the filter cake. In all domains, the supercharging pressure decreased with an increased filter cake permeability attenuation coefficient. As time increased, the decreased pore pressure caused by the filter cake increased, and a higher filter cake permeability attenuation coefficient was associated with a larger decrease in pore pressure, which contributed to smaller supercharging near the wellbore. Figure 6 shows that after a short period of time following the start of drilling, the supercharging difference with different filter cake permeability attenuation coefficients was small. However, as time increased, the supercharging difference continuously grew until a certain time point was reached, and the supercharging pressure decreased with the increase of the filter cake permeability attenuation coefficient. Over time, the supercharging difference decreased. Because the filter cake permeability decreased as the permeability attenuation coefficient of the filter cake increased, the filter cake was more likely to isolate the wellbore and formation; therefore, slight supercharging in the vicinity of the borehole could be seen when the filter cake had a higher permeability attenuation coefficient.

\subsection{Filter cake initial permeability control ratio}

The filter cake initial permeability control ratio controls the initial permeability of the filter cake, which can influence the rate of filtrate invasion into the formation. To clarify the effect of the initial filter cake permeability control ratio on supercharging, the pore pressure variations were analyzed, and the results when the initial filter cake permeability control ratio was considered as 3, 5, 7, and 9 are shown in Figures 7 and 8.

Figure 7 shows that at the four selected moments, the supercharging pressure decreased gradually along the radial direction and fell quickly across the filter cake. The supercharging pressure increased with the increase of the initial filter cake permeability control ratio. The decreased pore pressure caused by the filter cake increased with increasing time, and a higher initial filter cake permeability control ratio caused a lower decrease in pore pressure, which resulted in more severe supercharging in the vicinity of the borehole. The supercharging variations with four positions are shown in Figure 8. The supercharging pressure first increased and then decreased with increasing time, and a higher initial filter cake permeability control ratio contributed to a higher supercharging pressure. The supercharging difference with different initial filter cake permeability control ratios changed with time, first increasing and then decreasing as time passed. The reason for the supercharging phenomenon discussed above is that the filter cake permeability increased with the increased initial filter cake permeability control ratio, which led to a higher filtrate invasion rate; therefore, more severe supercharging appeared near the wellbore.

\subsection{Filter cake growth coefficient}

The filter cake growth coefficient controls the growth rate of the filter cake, and can also influence the rate of filtrate invasion into the formation. To investigate the effect of the filter cake growth coefficient on supercharging in the vicinity of the borehole, the pore pressure variations were analyzed for different filter cake growth coefficients of $0.001,0.002,0.003$, and 0.004. Figures 9 and 10 show the calculated results of supercharging variations with different times and positions, respectively.

Figure 9 shows that the supercharging pressure decreased gradually along the radial direction and fell quickly across the filter cake. The supercharging pressure decreased with the increase of the filter cake growth coefficient. As time increased, the decrease in pore pressure caused by the filter cake increased, which means that the most severe supercharging happened at the start of drilling under the current calculated examples. Figure 10 depicts the supercharging variations of four positions. With increasing time, the supercharging first increased, and the rate of increase was greater closer to the wellbore; after a short 

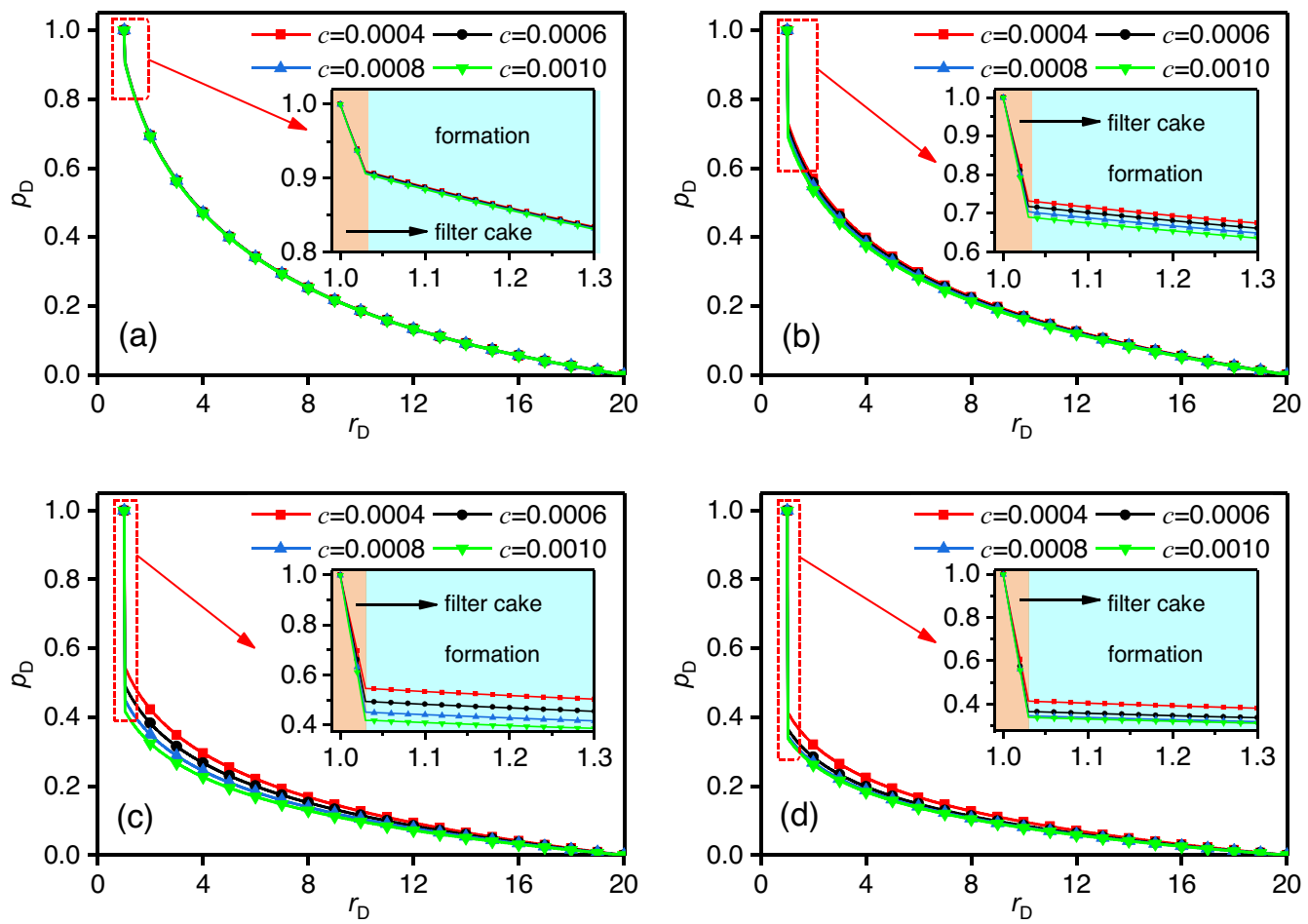

Fig. 5. Supercharging with different filter cake permeability attenuation coefficients. (a) $t=100 \mathrm{~s} ;$ (b) $t=500 \mathrm{~s} ;$ (c) $t=2000 \mathrm{~s}$; (d) $t=5000 \mathrm{~s}$.
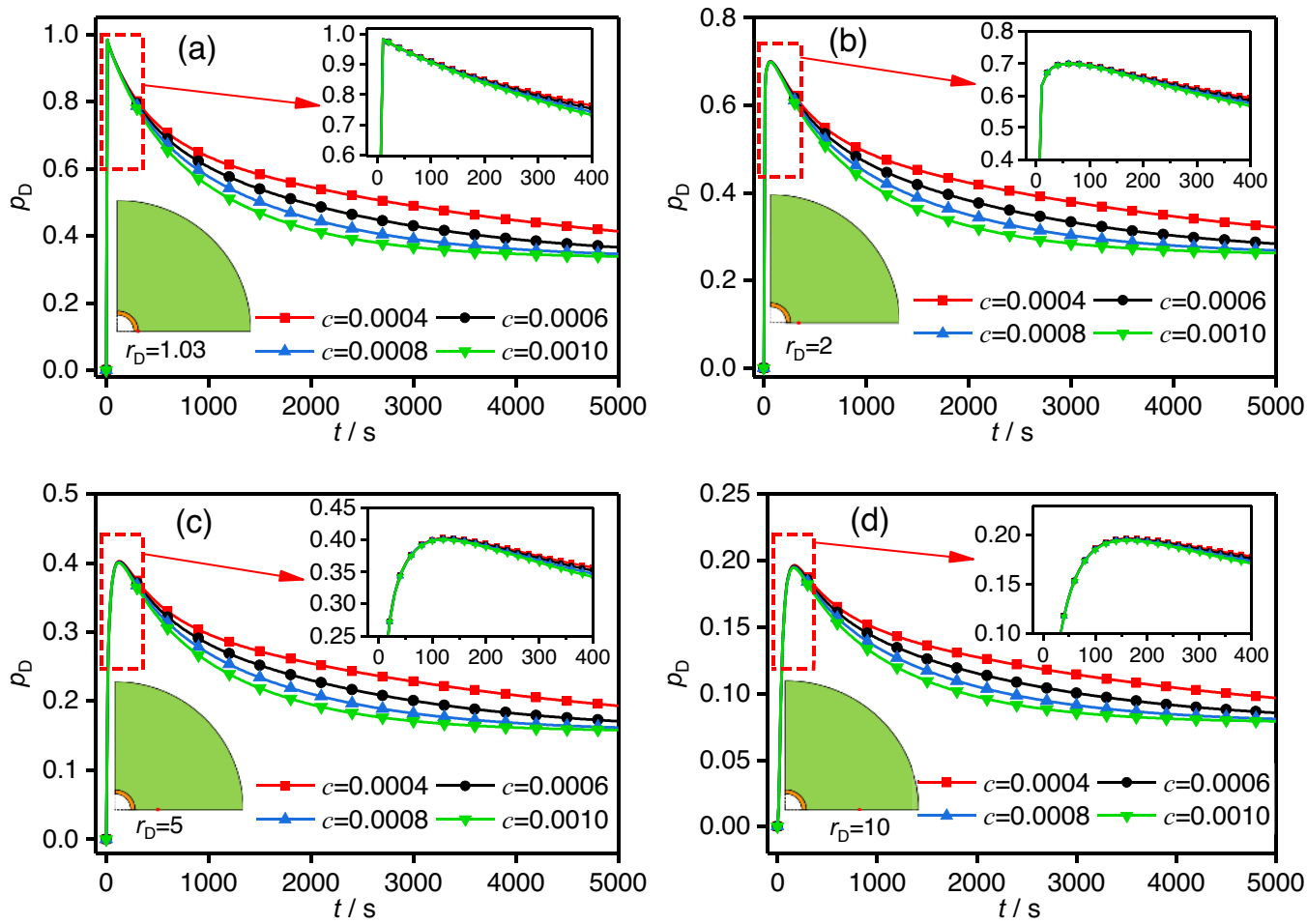

Fig. 6. Supercharging with different filter cake permeability attenuation coefficients. (a) $r_{D}=1.03 ;(\mathrm{b}) r_{D}=2 ;(\mathrm{c}) r_{D}=5$; (d) $r_{D}=10$. 

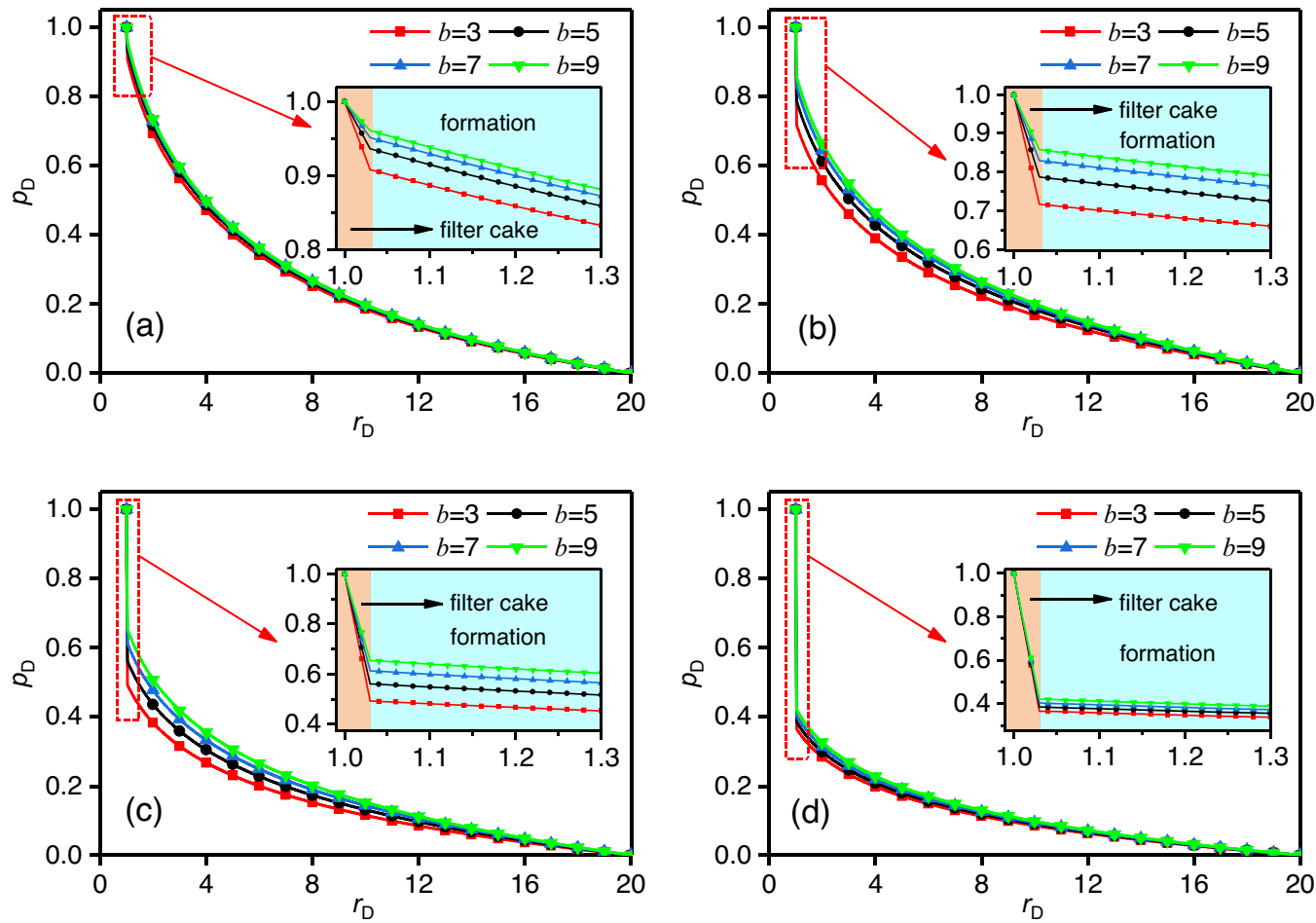

Fig. 7. Supercharging with different initial filter cake permeability control ratios. (a) $t=100 \mathrm{~s} ;$ (b) $t=500 \mathrm{~s} ;(\mathrm{c}) t=2000 \mathrm{~s}$; (d) $t=5000 \mathrm{~s}$.
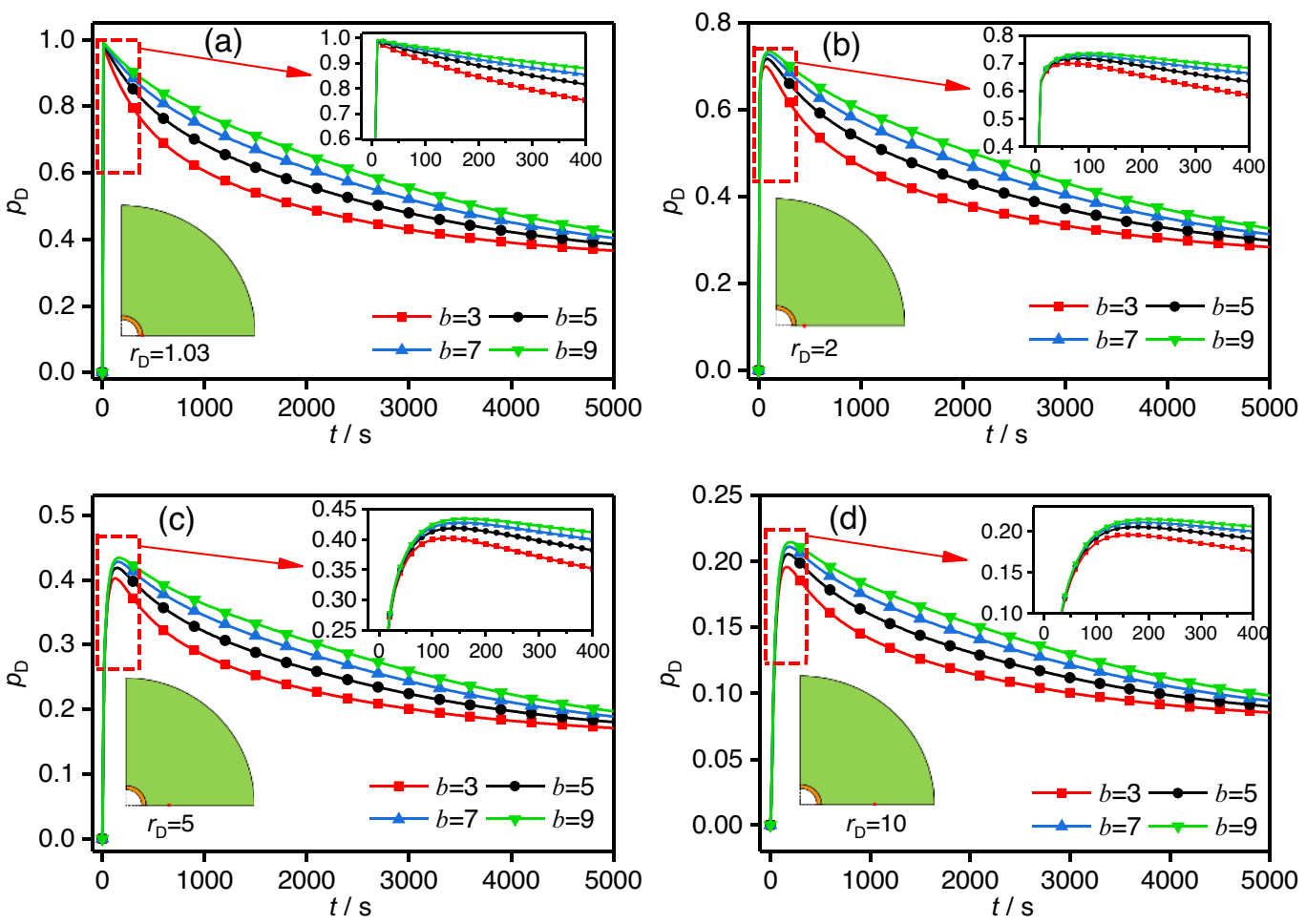

Fig. 8. Supercharging with different initial filter cake permeability control ratios. (a) $r_{D}=1.03 ;(\mathrm{b}) r_{D}=2 ;(\mathrm{c}) r_{D}=5 ;(\mathrm{d}) r_{D}=10$. 

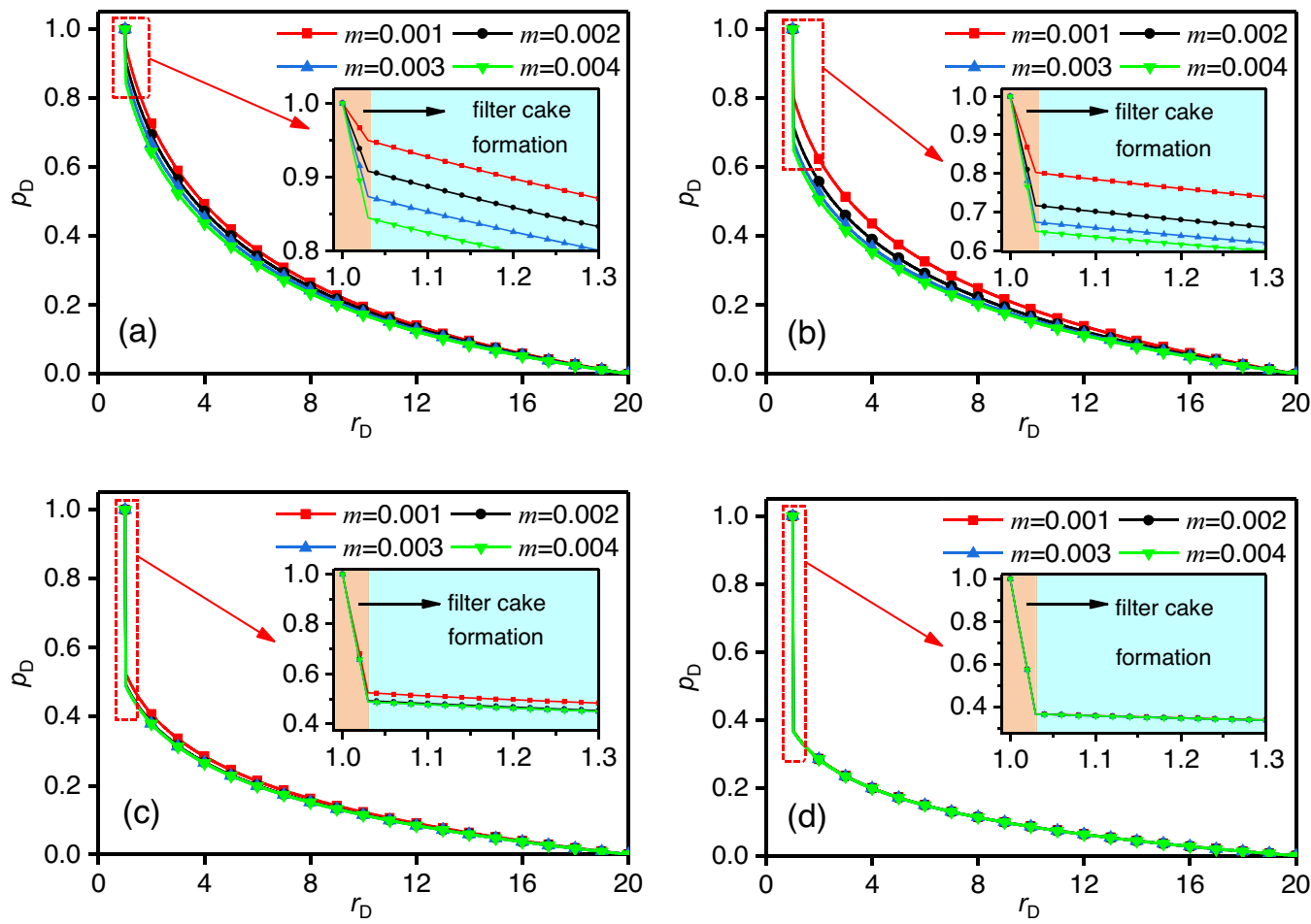

Fig. 9. Supercharging with different filter cake growth coefficients. (a) $t=100 \mathrm{~s} ;$ (b) $t=500 \mathrm{~s} ;(\mathrm{c}) t=2000 \mathrm{~s} ;(\mathrm{d}) t=5000 \mathrm{~s}$.
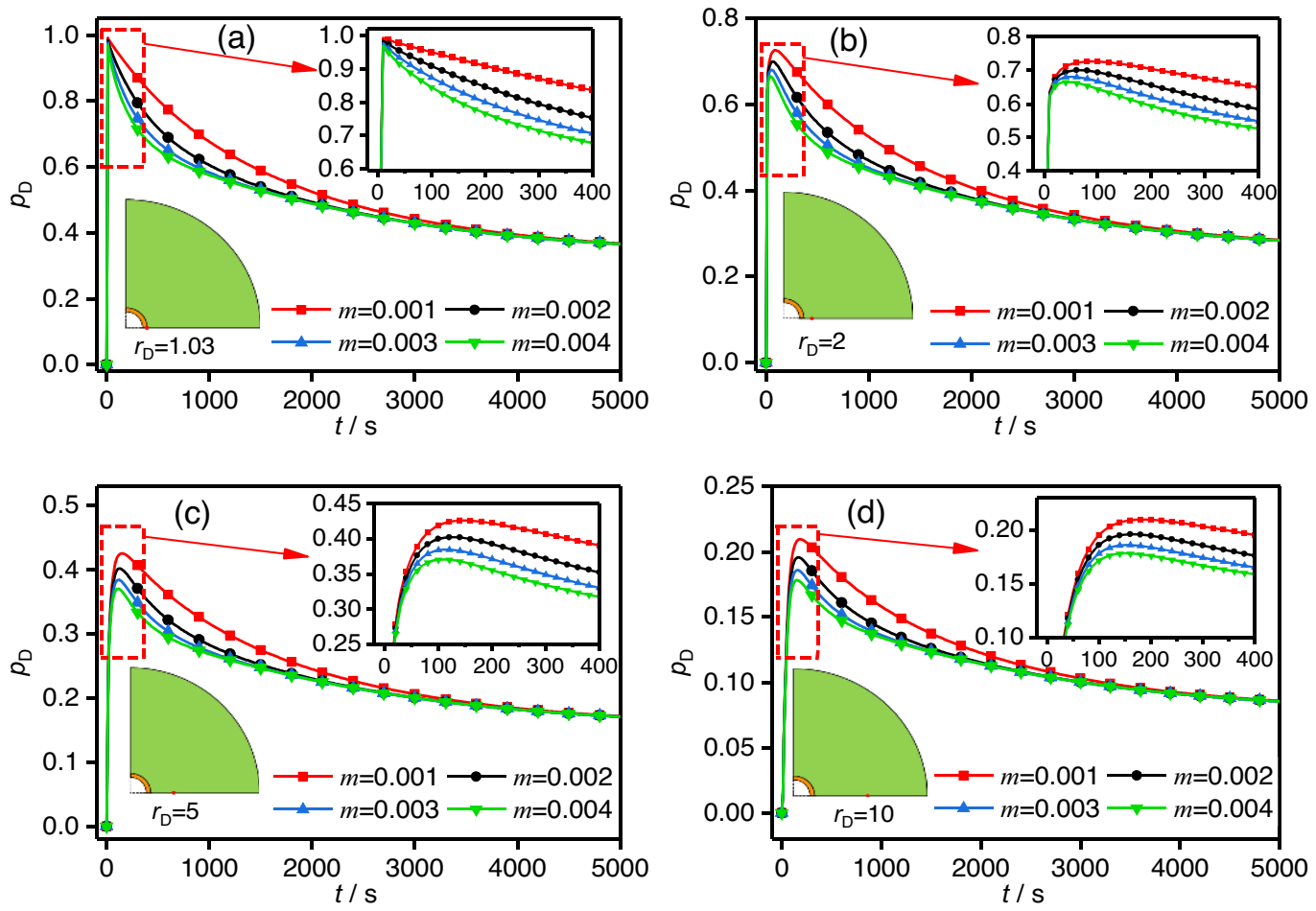

Fig. 10. Supercharging with different filter cake growth coefficients. (a) $r_{D}=1.03 ;$ (b) $r_{D}=2 ;$ (c) $r_{D}=5 ;\left(\right.$ d) $r_{D}=10$.

period of time, the supercharging decreased. The supercharging was also more sensitive to a small filter cake growth coefficient. The filter cake growth occurred more quickly when the filter cake had a larger growth coefficient, which limited the filtrate invasion rate; therefore, the supercharging was more slight. 

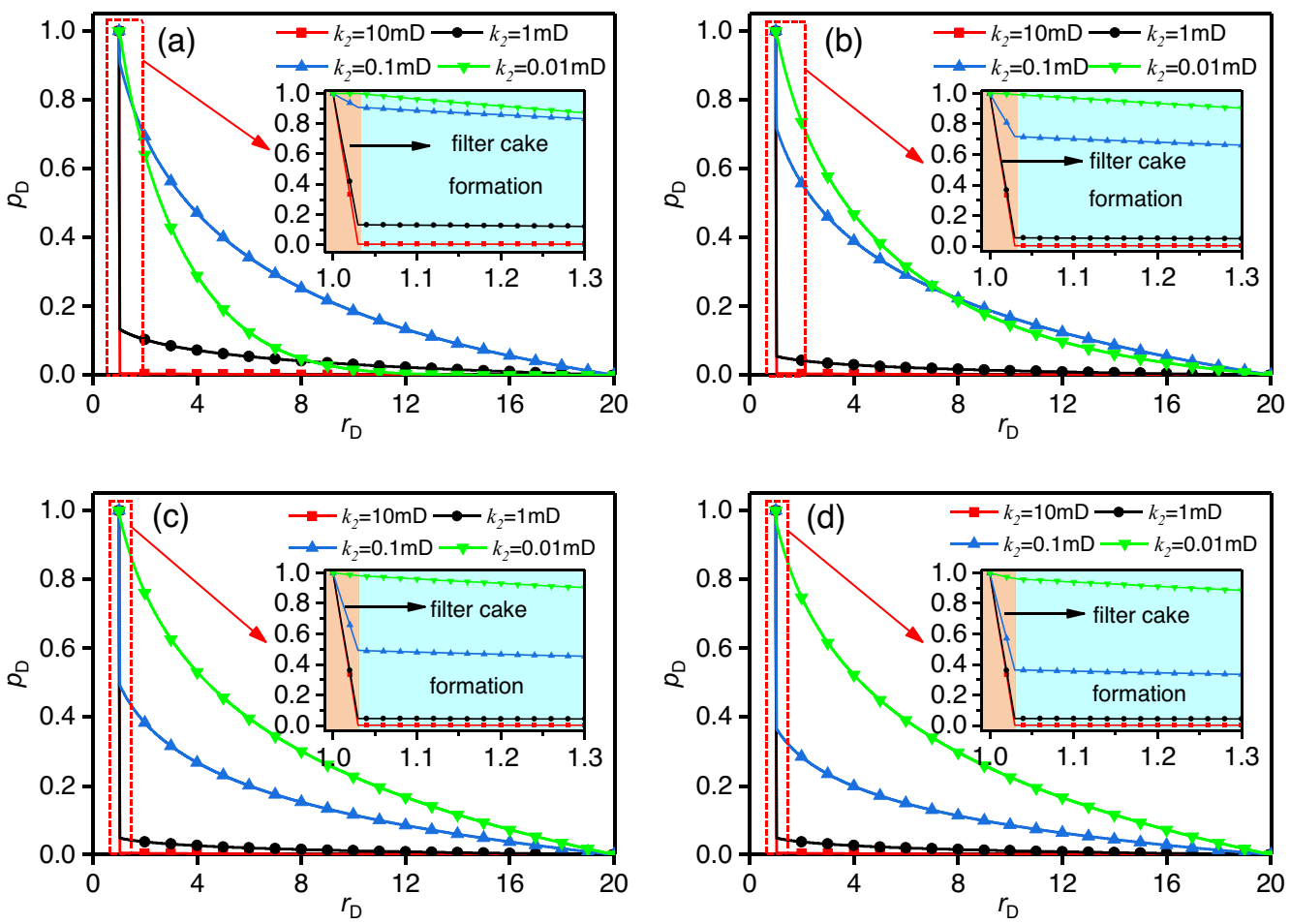

Fig. 11. Supercharging with different formation permeabilities. (a) $t=100 \mathrm{~s}$; (b) $t=500 \mathrm{~s} ;$ (c) $t=2000 \mathrm{~s} ;(\mathrm{d}) t=5000 \mathrm{~s}$.

\subsection{Formation permeability}

The formation is the main hydraulic diffusion medium during drilling, and its permeability is closely related to supercharging near the wellbore. To reveal the supercharging phenomena with different types of formations, the pore pressure in the vicinity of the borehole was investigated by considering formation permeabilities of $0.01,0.1,1$, and $10 \mathrm{mD}$ in the proposed model. The calculated results are shown in Figures 11 and 12.

Both Figures 11 and 12 show large differences compared with the previous analysis. When the formation had a high permeability, such as $10 \mathrm{mD}$, the supercharging pressure was almost equal to zero because of the higher hydraulic diffusion rate. As the formation permeability decreased, the supercharging approaching the wellbore was more severe in the early stage of filter cake formation, but supercharging far from the wellbore was not the highest when there was filtrate invasion into the lower permeability formations, such as in Figures 11a and 11b. The reason is that compared with higher permeability formations, lower formation permeability is associated with a smaller hydraulic diffusion rate; therefore, in lower permeability formations, the filtrate could not arrive at positions far from the wellbore during the same period of time. However, in the later stage of filter cake formation, such as in Figures 11c and 11d, supercharging increased with decrease of formation permeability in all domains. Figure 12 shows that supercharging in highpermeability formations can quickly dissipate. With decreasing formation permeability, the supercharging pressure first increases and then decreases; however, a special case should be noted that when the formation permeability is lower enough, the increased pore pressure can hardly dissipate. Therefore, it is necessary to pay more attention to supercharging in low-permeability formations.

\subsection{Formation porosity}

Formation porosity is a parameter of the hydraulic diffusion coefficient; changing formation porosity will change the filtrate diffusion rate in the formation and further result in variation of supercharging. To investigate the influence of formation porosity on supercharging, pore pressure variations near the wellbore were analyzed for different formation porosities of $0.05,0.10,0.15$ and 0.20 . The calculated results of supercharging are shown in Figures 13 and 14.

Figure 13 shows that the supercharging pressure decreased gradually along the radial direction and fell quickly across the filter cake, and that the decreased pore pressure caused by the filter cake increased with decreased formation porosity when other parameters were constant. Figure 14 shows that supercharging first increased and then decreased over time. A lower formation porosity caused a faster variation rate of supercharging, and the maximum supercharging pressure would form more quickly in lower porosity formations. The supercharging difference with different formation porosities increased early on but decreased with continuous increase in time. Based on the definition of the hydraulic diffusion coefficient, the hydraulic diffusion rate decreases with increased porosity when other parameters are constant; therefore, the supercharging in lowporosity formations is greater than that in high-porosity 

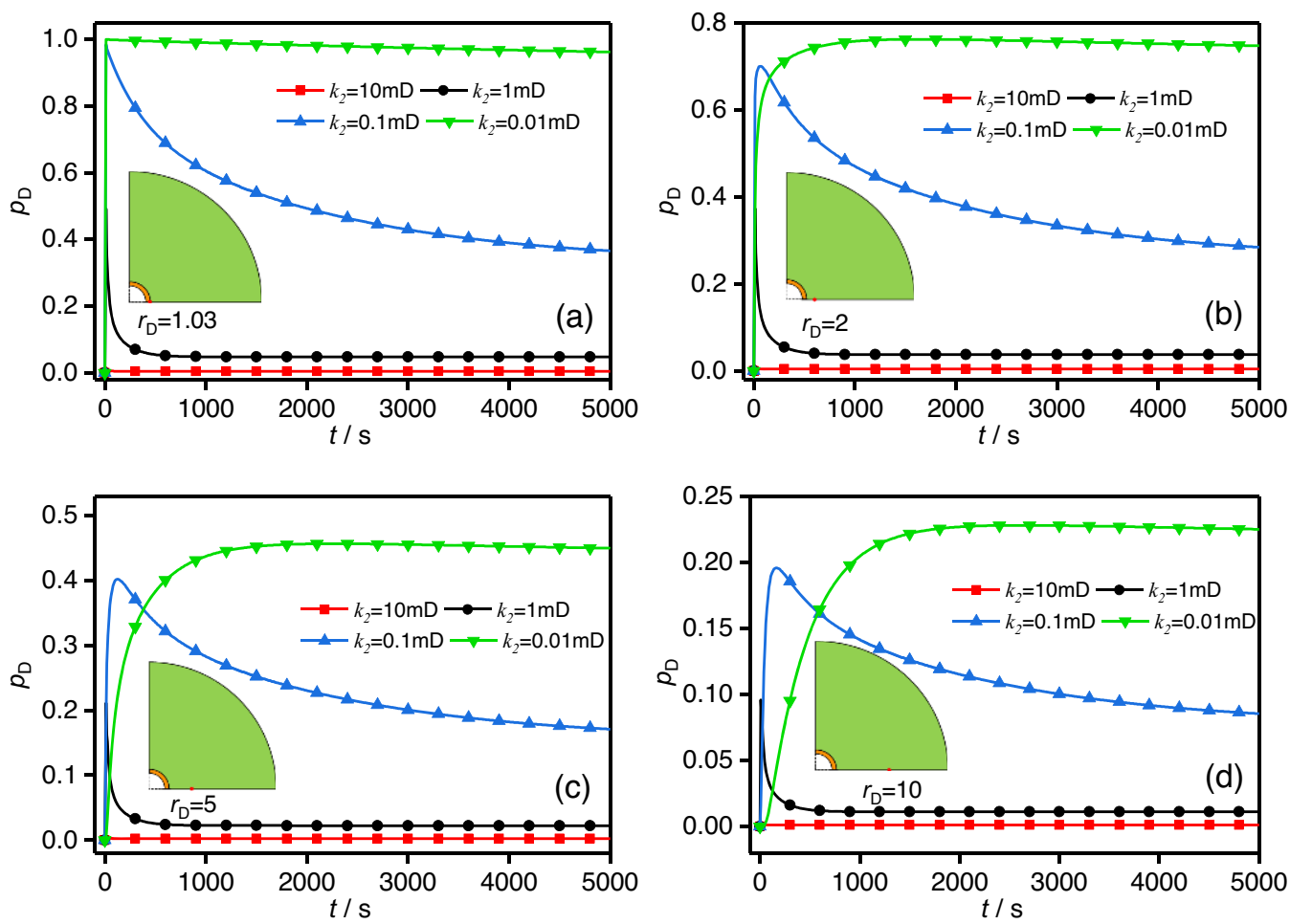

Fig. 12. Supercharging with different formation permeabilities. (a) $r_{D}=1.03$; (b) $r_{D}=2$; (c) $r_{D}=5$; (d) $r_{D}=10$.
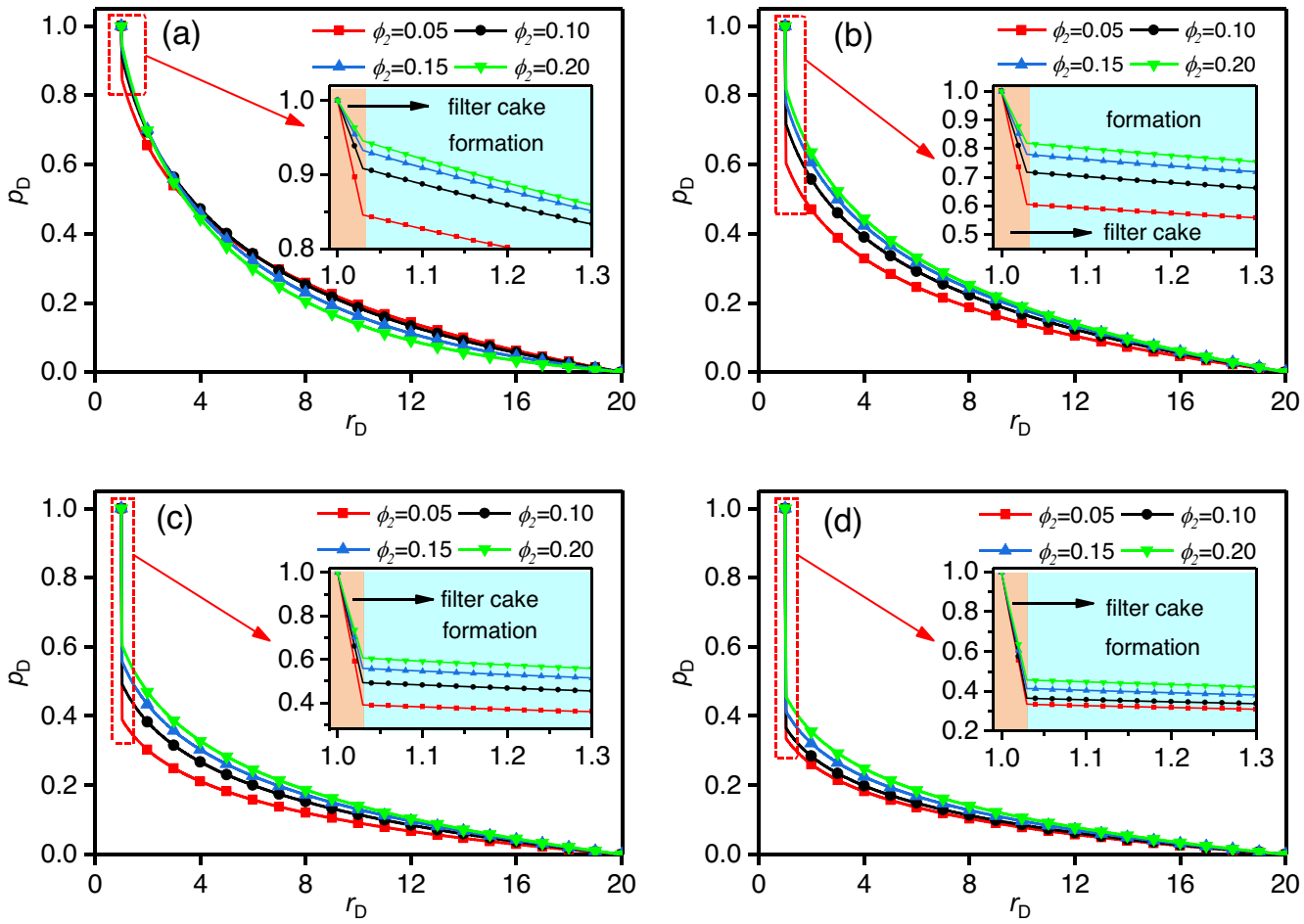

Fig. 13. Supercharging with different formation porosities. (a) $t=100 \mathrm{~s}$; (b) $t=500 \mathrm{~s} ;$ (c) $t=2000 \mathrm{~s} ;(d) t=5000 \mathrm{~s}$.

formations during a short period of time after the start of drilling. However, with increased time, the increased pore pressure would quickly dissipate in low-porosity formations because of the higher hydraulic diffusion rate, which would cause slight supercharging in the vicinity of the borehole. 

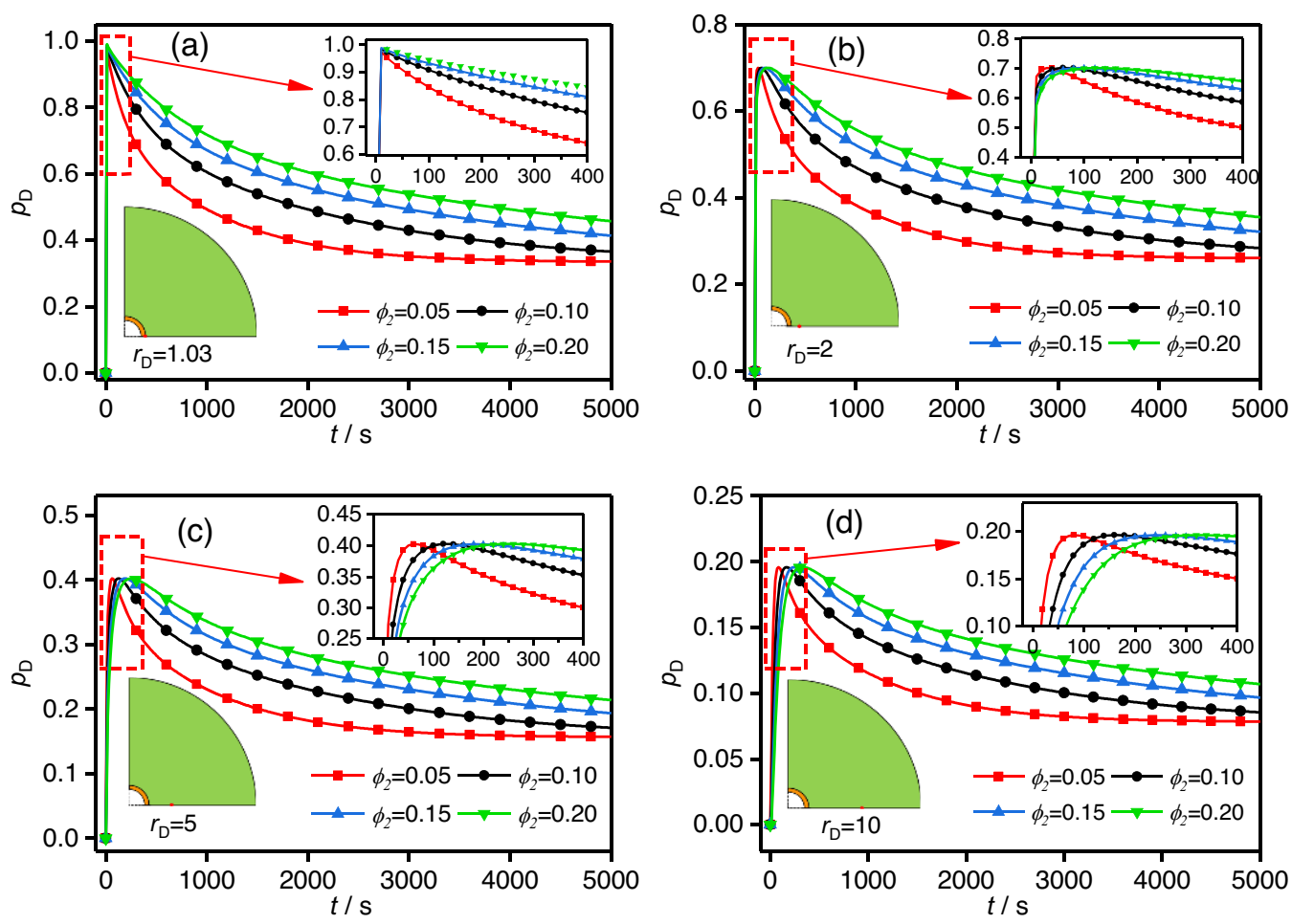

Fig. 14. Supercharging with different formation porosities. (a) $r_{D}=1.03 ;$ (b) $r_{D}=2 ;$ (c) $r_{D}=5 ;$ (d) $r_{D}=10$.

\subsection{Filtrate viscosity}

The filtrate viscosity directly affects the filtrate invasion rate between the wellbore and formation. To elucidate the supercharging variation rules with different filtrate viscosities, the supercharging pressure near the wellbore was calculated considering filtrate viscosities of $0.001,0.003$, 0.005, and 0.007 Pa.s; the results are shown in Figures 15 and 16 .

Figure 15 shows the supercharging variations with filtrate viscosity. In the early stage following the start of drilling, the supercharging pressure approaching the wellbore rose with increasing filtrate viscosity, whereas it decreased with distance away from the wellbore, as indicated in Figures 15a and 15b. Over time, the supercharging in all domains increased with increasing filtrate viscosity, as shown in Figures 15c and 15d. The supercharging pressure decreased gradually along the radial direction and fell quickly across the filter cake, and the decreased pore pressure caused by the filter cake increased over time. Figure 16 shows that supercharging first increased and then decreased over time. Higher filtrate viscosity was associated with a lower supercharging variation rate, and the maximum supercharging pressure would form more quickly when the filtrate had low viscosity. The reason for these variations in supercharging is that the filtrate diffusion rate decreases with increasing filtrate viscosity; therefore, a higher filtrate viscosity will cause lower supercharging during the early stage following the start of drilling. However, with increasing time, supercharging increased with the growth of filtrate viscosity because a higher filtrate viscosity causes a lower hydraulic diffusion rate. Therefore, more severe supercharging could be found near the wellbore.

\section{Discussions}

In this section, supercharging near the wellbore is first compared between four cases based on the proposed model, including: (I) no filter cake on the wellbore wall, (II) filter cake with time-dependent permeability and thickness on the wellbore wall, (III) filter cake with time-dependent permeability and a constant thickness of $3 \mathrm{~mm}$ on the wellbore wall, and (IV) a perfectly impermeable filter cake on the wellbore wall. The calculated results are shown in Figure 17; it should be noted that we divided the circle into four equal parts, and each part represents one of these cases.

Figure 17 shows that the supercharging variations were different in the four cases. With a perfectly impermeable filter cake on the wellbore wall, no supercharging appeared in the vicinity of the borehole. That is because a perfectly impermeable filter cake can completely isolate the diffusion process between the wellbore and formation. Soon after the start of drilling, the results with time-dependent filter cake thickness and permeability, compared with those with constant filter cake thickness, are closer to the results without filter cake, such as in Figures 17a-17c. During this time, the supercharging of cases I and II increased quickly. This was because the filter cake thickness was still small at this early time; thus, the filter cake's capability of restricting fluid seepage to the formation was limited. The supercharging 

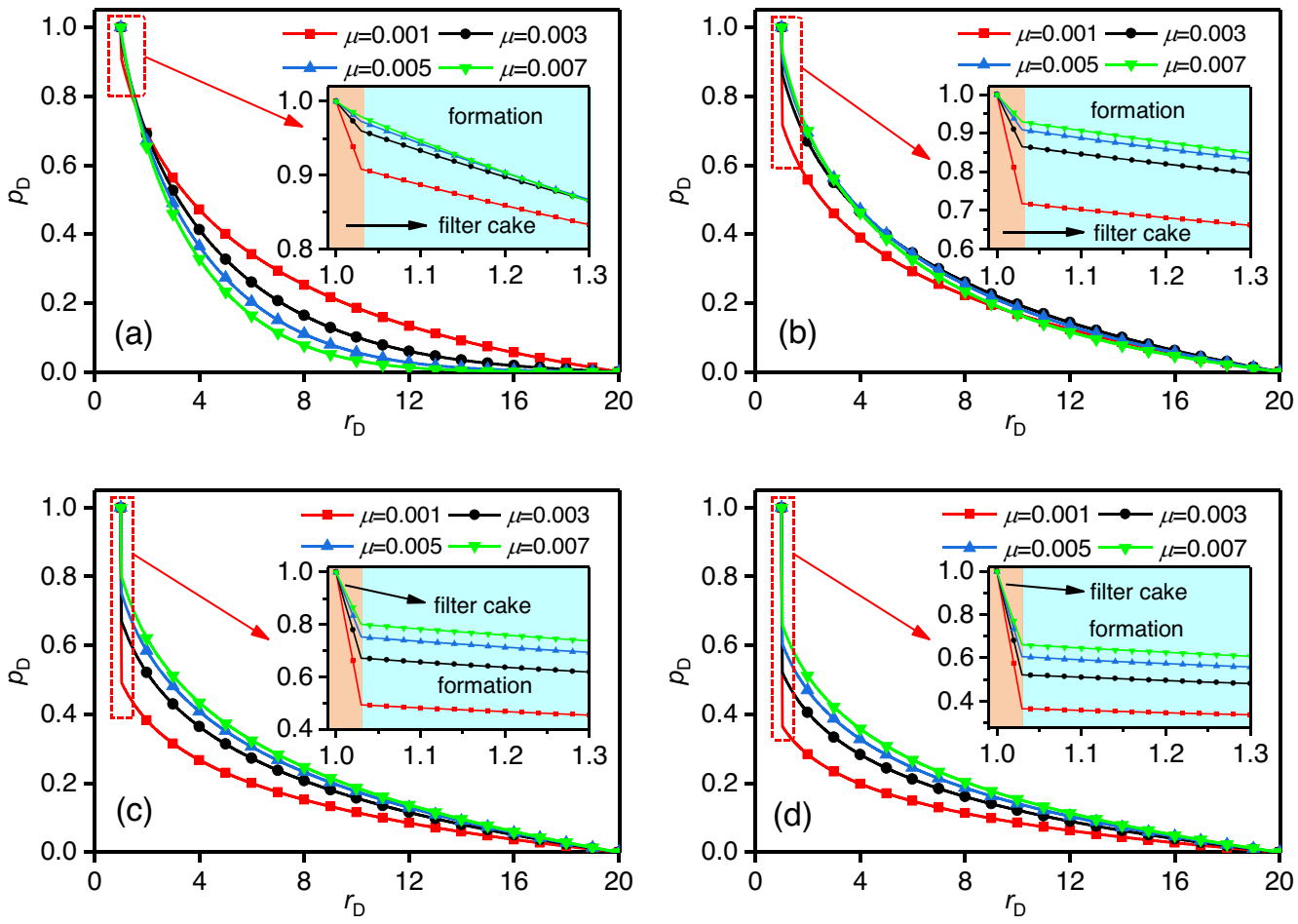

Fig. 15. Supercharging with different filtrate viscosities. (a) $t=100 \mathrm{~s}$; (b) $t=500 \mathrm{~s} ;$ (c) $t=2000 \mathrm{~s} ;$ (d) $t=5000 \mathrm{~s}$.
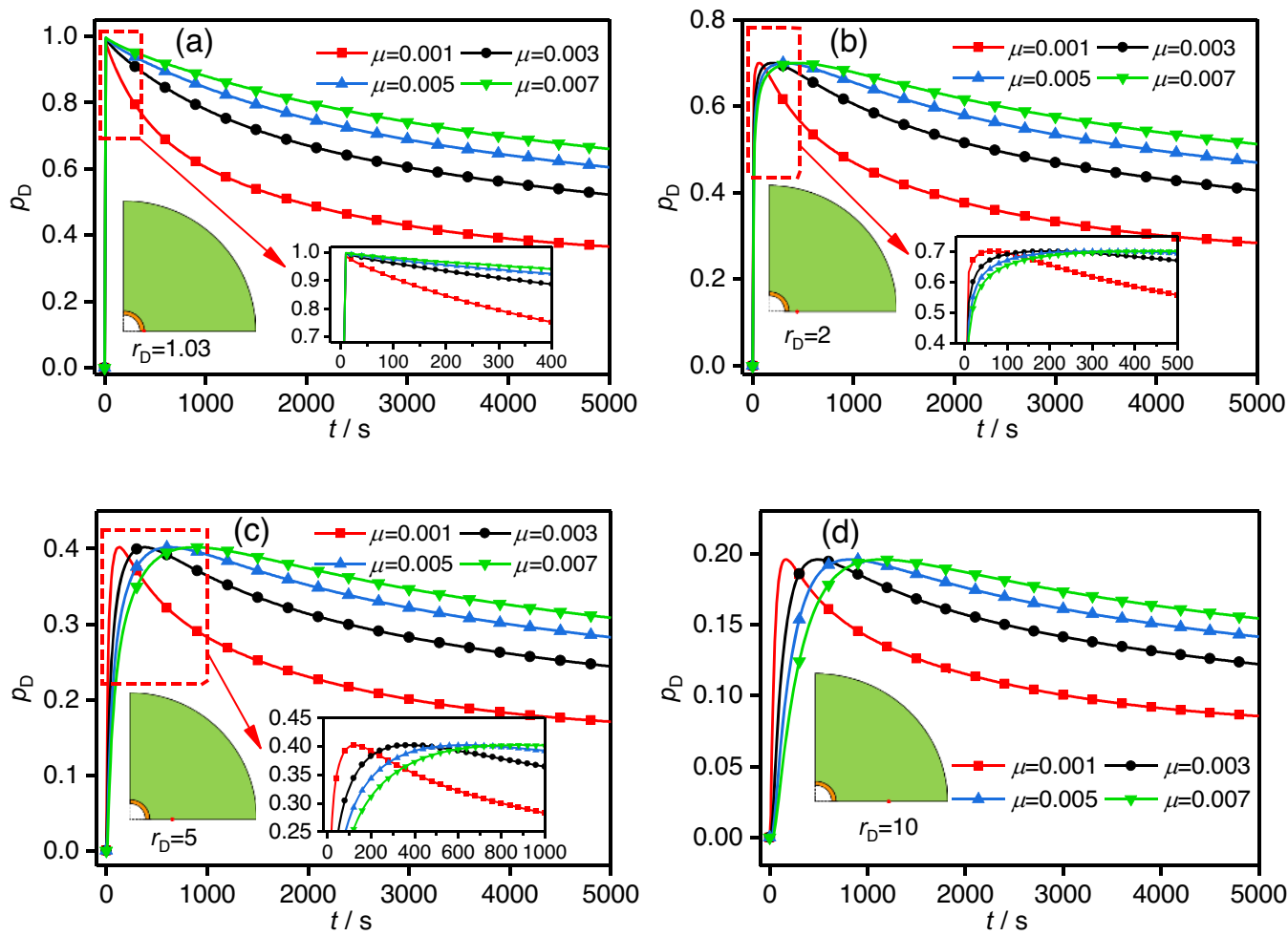

Fig. 16. Supercharging with different filtrate viscosities. (a) $r_{D}=1.03$; (b) $r_{D}=2$; (c) $r_{D}=5$; (d) $r_{D}=10$.

in case III also increased in this early period of time; however, the rate of increase was smaller than those in cases I and II because of the constant thickness assumed in case
III. With increasing time, the supercharging of case I grew continuously and then became stable, whereas the supercharging in cases II and III first increased and then 

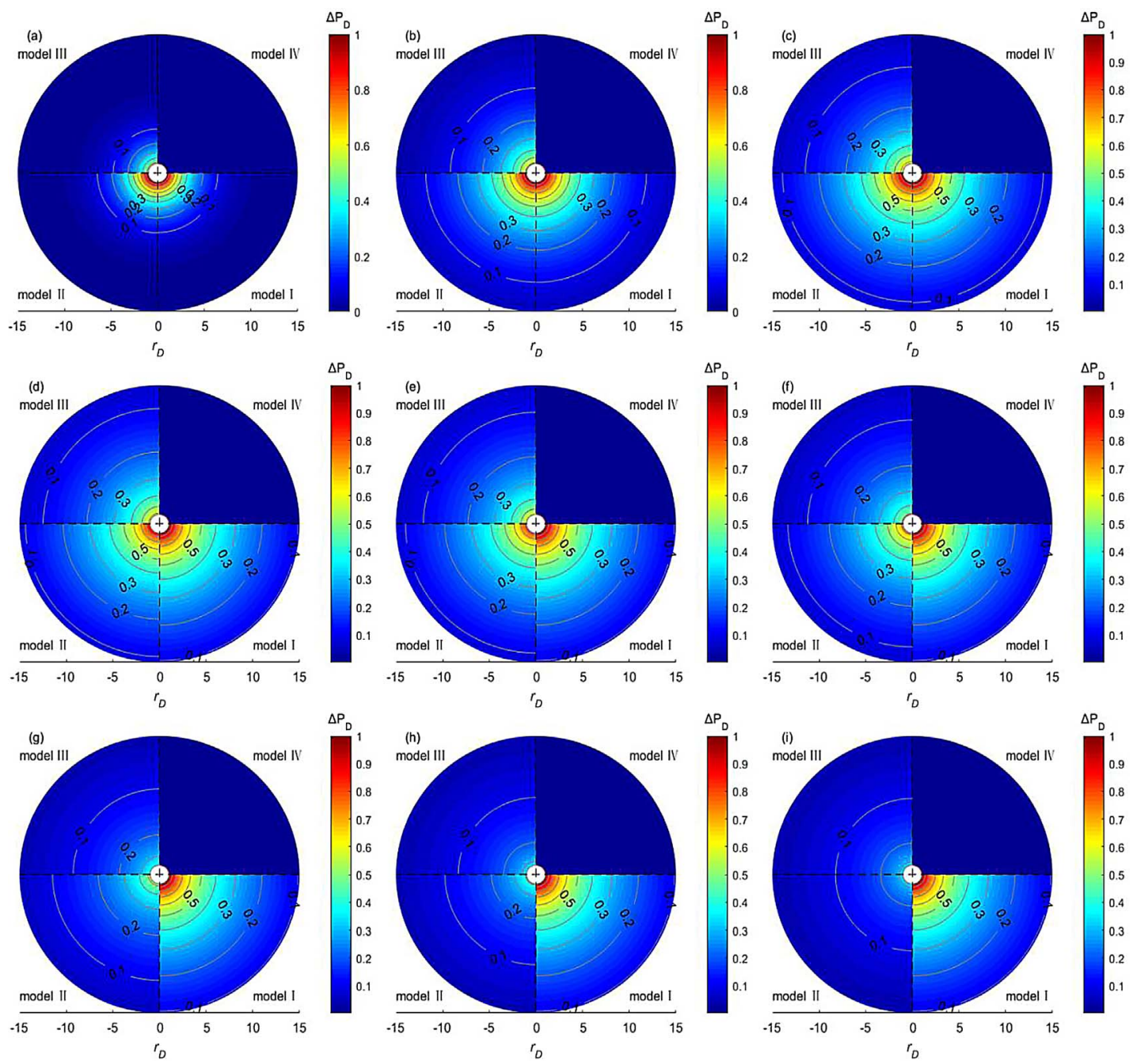

Fig. 17. Supercharging comparison of four models at different times. (a) $t=10 \mathrm{~s}$; (b) $t=50 \mathrm{~s} ;$ (c) $t=100 \mathrm{~s}$; (d) $t=500 \mathrm{~s}$; (e) $t=1000 \mathrm{~s}$; (f) $t=2000 \mathrm{~s}$; (g) $t=5000 \mathrm{~s}$; (h) $t=10000 \mathrm{~s}$; (i) $t=50000 \mathrm{~s}$.

decreased. Although the variation trends were the same for the two cases, it should be noted that the supercharging of case II was higher than that of case III. This was because the capability of the filter cake with time-dependent thickness and permeability to restrict fluid seepage was always weaker than that of the filter cake with time-dependent permeability and constant thickness. However, at a later time, such as $t=50,000 \mathrm{~s}$, the supercharging of case II approached those with constant filter cake thickness because the filter cake properties in both cases almost reached the final equilibrium values.

The results analyzed above demonstrate that supercharging near the wellbore is closely related to timedependent filter cake thickness and permeability, and ignoring the presence of filter cake, or assuming that the filter cake is impermeable or has a constant thickness, will either underestimate or overestimate the supercharging pressure. The pore pressure variations have a direct influence on effective stress near the wellbore, and result in variation of rock strength. In formation testing while drilling or reservoir damage analysis, accurate inversion of formation parameters depends on the real formation pressure and invasion radius; however, supercharging will disturb the original formation pressure, and if the supercharging pressure is not considered or its prediction is not accurate enough when formation parameter assessment is conducted, the results may not be accurate, which may mislead industry professionals into making inappropriate plans or decisions. Therefore, it is necessary to consider the timedependent properties during filter cake growth in wellbore stability evaluation, reservoir damage analysis, and formation testing while drilling.

Aside from the time-dependent properties of the filter cake, the other main factors that influence supercharging should also be given more attention. To reveal the degree of influence of each factor on supercharging more intuitively, the influences of the formation permeability, formation porosity, initial filter cake permeability control ratio, permeability attenuation coefficient, growth coefficient, filter cake porosity, overbalance pressure, and filtrate viscosity were analyzed based on the basic parameters in Table 1. In the calculation process, the analysis object 


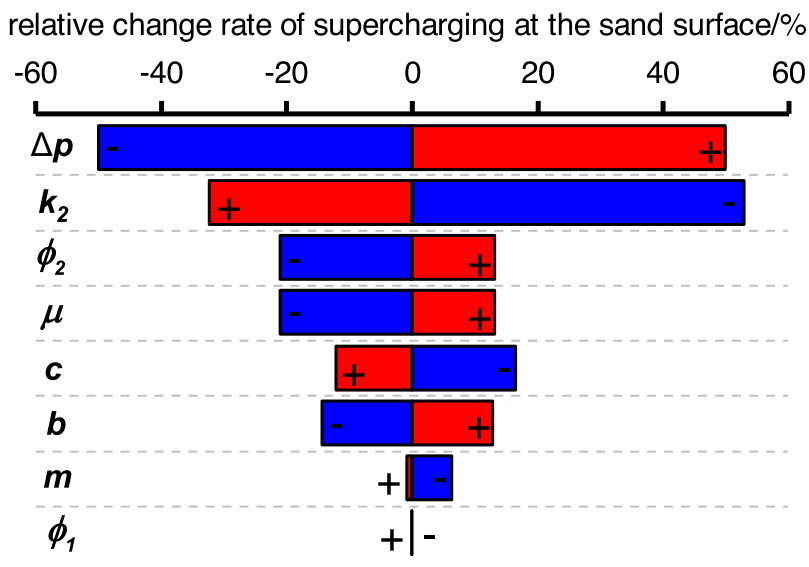

Fig. 18. Sensitivity analysis of influencing factors.

was adjusted by $50 \%$ upward $(+)$ and downward $(-)$, respectively, while the remaining parameters were unchanged. The calculated results are shown in Figure 18. The degrees of influence of these factors on supercharging decreased in the following order: overbalance pressure > formation permeability $>$ formation porosity $\approx$ filtrate viscosity $>$ filter cake permeability attenuation coefficient $>$ initial filter cake permeability control ratio $>$ filter cake growth coefficient $>$ filter cake porosity.

Therefore, in drilling practice, to weaken supercharging in the vicinity of the borehole, the following strategies could be adopted: (1) minimizing the overbalance pressure during drilling, or adopting underbalanced drilling or accurate management of pressure drilling technology; (2) optimizing the drilling fluid system, type, and materials so that a dense and high-quality filter cake can form quickly during drilling to isolate the wellbore and prevent mud filtrate invasion; (3) ensuring precise operation at the rig site to avoid more severe supercharging from human causes.

The supercharging pressure prediction model proposed in this paper is focused on the influence of time-dependent filter cake thickness and permeability. With this model, supercharging in the vicinity of the borehole with different conditions, including time-dependent permeability and thickness of the filter cake, time-dependent filter cake permeability with constant thickness, a perfectly impermeable filter cake, or absence of filter cake on the wellbore wall, can be described. However, the model also has some limitations. For example, the fluid considered in this paper is a singlephase fluid, and supercharging under multi-phase flow conditions was not considered. And the dynamic drilling conditions were not coupled in the model to describe the filter cake formation process. In addition, only the hydraulic diffusion process is considered in the supercharging model; the supercharging phenomenon of multi-physics coupling is not involved. Thus, more complete modeling by considering such factors is required in future work.

\section{Conclusion}

In the present paper, an analytical model of supercharging in the vicinity of the borehole has been proposed that considers time-dependent properties of filter cake growth. The influences of the main parameters on supercharging were analyzed, and the supercharging phenomena of different cases were also investigated. The main conclusions can be drawn as follows:

1. Supercharging in the vicinity of the borehole is closely related to time-dependent filter cake thickness and permeability; hence, overlooking the presence of the filter cake or assuming impermeability or constant thickness of the filter cake will lead to either underestimation or overestimation of the supercharging pressure.

2. The supercharging pressure decreases gradually along the radial direction and falls quickly across the filter cake, while the decreased pore pressure caused by the filter cake increases over time.

3. The degrees of influence of different parameters on supercharging decrease in the following order: overbalance pressure $>$ formation permeability $>$ formation porosity $\approx$ filtrate viscosity $>$ filter cake permeability attenuation coefficient $>$ initial filter cake permeability control ratio $>$ filter cake growth coefficient $>$ filter cake porosity.

4. Supercharging can quickly dissipate in high-permeability formations; however, dissipation is more difficult in low-permeability formations, and severe supercharging near the wellbore will appear in such formations. A faster growth rate of dense filter cake, a lower filtrate viscosity, a smaller overbalance pressure, and precise operation are required to weaken supercharging.

Acknowledgments. This work was supported by the National Natural Science Foundation of China (Grant No. 41874216), the Fok Ying-Tong Education Foundation, China (Grant No. 171097), the Sichuan Science and Technology Program (Grant No. 2020JDJQ0055), and the Youth Scientific and Technological Innovation Team Foundation of Southwest Petroleum University (Grant No. 2019CXTD09).

\section{References}

Banerjee R., Thambynayagam R.K.M., Spath J. (2006) A method for analysis of pressure response with a formation tester influenced by supercharging, in: The 2006 SPE Russian Oil and Gas Technical Conference and Exhibition, Moscow, Russia, 3-6 October, SPE-102413-MS. https://doi.org/ 10.2118/102413-MS.

Bruno M.S., Nakagawa F.M. (1991) Pore pressure influence on tensile fracture propagation in sedimentary rock, Int. J. Rock Mech. Min. Sci. Geomech. Abstr. 28, 4, 261-273. https://doi. org/10.1016/0148-9062(91)90593-B.

Ceyhan A.G., Bravo M., Walrond K. (2016) Supercharging assessment in formation pressure measurements made while drilling by deliberately pulsed circulation in a carbonate reservoir, in: The SPWLA 57th Annual Logging Symposium, Reykjavik, Iceland, 25-29 June, SPWLA-2016-TTTT.

Chang Y., Hammond P.S., Pop J.J. (2008) When should we worry about supercharging in formation-pressure-while-drilling measurements? SPE Reserv. Evalu. Eng. 11, 1, 165-174. https://doi.org/10.2118/92380-PA. 
Civan F. (2016) Reservoir formation damage fundamentals, modeling, assessment, and mitigation, 3rd edn., Gulf Publishing Company, Houston, Texas.

Dabiri A., Afkhami M., Fallah H. (2013) Reservoir formation damage due to mud filtration, Am. J. Chem. Eng. 1, 1, 1-5. https://doi.org/10.11648/j.ajche.20130101.11.

Di D.J., Tao G., Wang B., Chen X., Sun J.M. (2014) Numerical analysis of the effects of downhole dynamic conditions on formation testing while drilling, Petrol. Sci. 11, 3, 391-400. https://doi.org/10.1007/s12182-014-0353-2.

Feng Y.C., Li X.R., Gary K.E. (2018a) An easy-to-implement numerical method for quantifying time-dependent mudcake effects on near-wellbore stresses, J. Pet. Sci. Eng. 164, 501514. https://doi.org/10.1016/j.petrol.2018.01.051.

Feng Y.C., Li X.R., Grar K.E. (2018b) Mudcake effects on wellbore stress and fracture initiation pressure and implications for wellbore strengthening, Petrol. Sci. 15, 2, 319-334. https://doi.org/10.1007/s12182-018-0218-1.

Fisher K.A., Wakeman R.J., Chiu T.W., Meuric O.F.J. (2000) Numerical modelling of cake formation and fluid loss from non-newtonian muds during drilling using eccentric/concentric drill strings with/without rotation, Chem. Eng. Res. Des. 78, 5, 707-714. https://doi.org/10.1205/026387600527888.

Guayacán-Carrillo L.M., Ghabezloo S., Sulem J., Seyedi D.M. (2017) Effect of anisotropy and hydro-mechanical couplings on pore pressure evolution during tunnel excavation in lowpermeability ground, Int. J. Rock Mech. Min. Sci. 97, 1-14. https://doi.org/10.1016/j.ijrmms.2017.02.016.

Hadibeik H., Chen D.D., Proett M., Eyuboglu S., Torres-Verdín C. (2012) Petrophysical properties of unconventional lowmobility reservoirs (shale gas and heavy oil) by using newly developed adaptive testing approach, in: The 2012 SPE Annual Technical Conference and Exhibition, San Antonio, Texas, USA, 8-10 October, SPE-159172-MS. https://doi.org/ 10.2118/159172-MS.

Halafawi I.M., Avram I.L. (2019) Wellbore instability prediction and performance analysis using Poroelastic modeling, J. Oil Gas Petrochem. Sci. 2, 2, 93-106. https://doi.org/10.30881/ jogps.00028.

Hammond P.S., Pop J.J. (2005) Correcting Supercharging in formation-pressure measurements made while drilling, in: The 2005 SPE Annual Technical Conference and Exhibition, Dallas, Texas, USA, 9-12 October, SPE-95710-MS. https://doi.org/10.2118/95710-MS.

Hashemzadeh S.M., Hajidavalloo E. (2016) Numerical investigation of filter cake formation during concentric/eccentric drilling, J. Pet. Sci. Eng. 145, 161-167. https://doi.org/ 10.1016/j.petrol.2016.03.024.

Jaffal H.A., El Mohtar C.S., Gray K.E. (2017) Modeling of filtration and mudcake buildup: an experimental investigation, J. Nat. Gas Sci. Eng. 38, 1-11. https://doi.org/10.1016/ j.jngse.2016.12.013.

Jaffal H.A., El Mohtar C.S., Gray K.E. (2018) A predictive filtration model considering mudcake compressibility and nonuniform properties' profiles, J. Nat. Gas Sci. Eng. 55, 174181. https://doi.org/10.1016/j.jngse.2018.05.001.

Jia S.P., Wen C.X., Deng F.C., Yan C.L., Xiao Z.Q. (2019) Coupled THM modelling of wellbore stability with drilling unloading, fluid flow, and thermal effects considered, Math. Probl. Eng. 142, 5, 1166-1167. https://doi.org/10.1155/ 2019/5481098.

Khaled M.S., Shokir E.M. (2017) Effect of drillstring vibration cyclic loads on wellbore stability, in: SPE Middle East Oil \&
Gas Show and Conference, Manama, Kingdom of Bahrain, 6-9 March, SPE-183983-MS. https://doi.org/10.2118/ 183983-MS.

Li G., Cai W.Q., Meng Y.F., Wang L., Wang L.M., Zhang X.B. (2017) Experimental evaluation on the damages of different drilling modes to tight sandstone reservoirs, Nat. Gas Ind. 37, 2, 69-76. https://doi.org/10.3787/j.issn.1000-0976.2017.02.009.

Ling K.G., Zhang H., Shen Z., Ghalambor A., Han G.Q., He J., Pei P. (2015) A new approach to estimate invasion radius of water-based-drilling-fluid filtrate to evaluate formation damage caused by overbalanced drilling, SPE Drill. Complet. 30, 1, 2737. SPE-168184-PA. https://doi.org/10.2118/168184-PA.

Liu C., Abousleiman Y.N. (2018) Multiporosity/multipermeability inclined-wellbore solutions with mudcake effects, SPE J. 23, 5, 1723-1747. https://doi.org/10.2118/191135-PA.

Liu Q., Santamarina J.C. (2018) Mudcake growth: Model and implications, J. Pet. Sci. Eng. 162, 251-259. https://doi.org/ 10.1016/j.petrol.2017.12.044.

Liu J.J., Yu X.B., Zhao J.Z. (2013) Numerical simulation of geostress and pore pressure evolution around oil or water well under different injection-production ratio, Math. Probl. Eng. 2013, 604748. https://doi.org/10.1155/2013/604748.

Liu Y., Ma T.S., Wu H., Chen P. (2020) Investigation on mechanical behaviors of shale cap rock for geological energy storage by linking macroscopic to mesoscopic failures, $J$. Energy Storage 29, 101326. https://doi.org/10.1016/j. est.2020.101326.

Ma T.S., Chen P., Han X. (2015) Simulation and interpretation of the pressure response for formation testing while drilling, $J$. Nat. Gas Sci. Eng. 23, 259-571. https://doi.org/10.1016/j. jngse.2015.01.044.

Ma T.S., Chen P., Wang X.D., Guo Z.X., Liu Z.Q. (2016) Numerical method of pore pressure propagation around the borehole for shale gas reservoirs, Acta Petrol. Sin. 37, 4, 660 671. https://doi.org/10.7623/syxb201605010.

Ma T.S., Peng N., Chen P. (2020) Filter cake formation process by involving the influence of solid particle size distribution in drilling fluids, J. Nat. Gas Sci. Eng. 79, 103350. https://doi. org/10.1016/j.jngse.2020.103350.

Meng M., Zamanipour Z., Miska S., Yu M., Ozbayoglu E.M. (2019) Dynamic stress distribution around the wellbore influenced by surge/swab pressure, J. Pet. Sci. Eng. 172, 1077-1091. https://doi.org/10.1016/j.petrol.2018.09.016.

Mohajerani M., Delage P., Sulem J., Monfared M., Tang A.M., Gatmiri B. (2012) A laboratory investigation of thermally induced pore pressures in the Callovo-Oxfordian claystone, Int. J. Rock Mech. Min. Sci. 52, 112-121. https://doi.org/ 10.1016/j.ijrmms.2012.02.012.

Parn-anurak S., Engler T.W. (2005) Modeling of fluid filtration and near-wellbore damage along a horizontal well, J. Pet. Sci. Eng. 46, 3, 149-160. https://doi.org/10.1016/j.petrol.2004.12.003.

Rabbani A., Salehi S. (2017) Dynamic modeling of the formation damage and mud cake deposition using filtration theories coupled with SEM image processing, J. Nat. Gas Sci. Eng. 42, 157-168. https://doi.org/10.1016/j.jngse.2017.02.047.

Ribeiro J.M., Eler F.M., Martins A.L., Scheid C.M., Calçada L.A., da Cruz Meleiro L.A. (2017) A simplified model applied to the barite sag and fluid flow in drilling muds: Simulation and experimental results, Oil Gas Sci. Technol. - Rev. IFP Energies nouvelles 72, 4, 23. https://doi.org/10.2516/ogst/2017016.

Rice J.R. (2006) Heating and weakening of faults during earthquake slip, J. Geophys. Res. Solid Earth 111, B05311. https://doi.org/10.1029/2005JB004006. 
Roshan H., Rahman S.S. (2010) A fully coupled chemoporoelastic analysis of pore pressure and stress distribution around a wellbore in water active rocks, Rock Mech. Rock Eng. 44, 2, 199-210. https://doi.org/10.1007/s00603-010-0104-7.

Roshan H., Rahman S.S. (2011) Analysis of pore pressure and stress distribution around a wellbore drilled in chemically active elastoplastic formations, Rock Mech. Rock Eng. 44, 5, 541-552. https://doi.org/10.1007/s00603-011-0141-x.

Shi W.Y., Yao Y.D., Cheng S.Q., Li H., Wang M., Cui N., Zhang C.W., Li H., Tu K., Shi Z.L. (2021) Investigation on the pressure response behavior of two-layer vertical mixed boundary reservoir: Field cases in Western Sichuan XC gas field, China, Oil Gas Sci. Technol. - Rev. IFP Energies nouvelles 76, 2. https://doi.org/10.2516/ogst/2020082.

Tran M.H., Abousleiman Y.N., Nguyen V.X. (2011) The effects of filter-cake buildup and time-dependent properties on the stability of inclined wellbores, SPE J. 16, 4, 1010-1028. https://doi.org/10.2118/135893-PA.

Ubedullah A., Cheng Y.F., Li Q.C., Georgia G.M. (2019) Simulating the effect of subsurface stresses and transient pore pressure on wellbore stability in subsea horizontal wells, Energy
Sources Part A Recovery Utilization \& Env. Effects 41, 16, 2028-2038. https://doi.org/10.1080/15567036.2018.1549150.

Veisi E., Hajipour M., Delijani E.B. (2020) Experimental study on thermal, rheological and filtration control characteristics of drilling fluids: Effect of nanoadditives, Oil Gas Sci. Technol. Rev. IFP Energies nouvelles 75, 36. https://doi.org/10.2516/ ogst $/ 2020033$.

Yao R., Jiang G., Li W., Deng T., Zhang H. (2014) Effect of water-based drilling fluid components on filter cake structure, Powder Technol. 262, 51-61. https://doi.org/10.1016/j. powtec.2014.04.060.

Zaher A., Sirju C. (2014) Quantifying the effects of rock and fluid properties on point probe formation pressure measurements, in: The SPWLA 55th Annual Logging Symposium, 2014, Abu Dhabi, United Arab Emirates, 18-22 May, SPWLA-2014-RRR.

Zheng L.H., Liu H., Zeng H., Wu T., Zhang W.C., Wang C. (2019) Evaluation of working fluid damage in fractured reservoirs using flow rate instead of permeability, Nat. Gas Ind. 39, 12, 74-80. https://doi.org/10.3787/j.issn.10000976.2019.12.009. 